\title{
Evaluation of biomass burning aerosols in the HadGEM3 climate model with observations from the SAMBBA field campaign
}

\author{
Ben T. Johnson ${ }^{1}$, James M. Haywood ${ }^{1,2}$, Justin M. Langridge ${ }^{1}$, Eoghan Darbyshire ${ }^{3}$, William T. Morgan ${ }^{3}$, \\ Kate Szpek $^{1}$, Jennifer K. Brooke ${ }^{1}$, Franco Marenco ${ }^{1}$, Hugh Coe ${ }^{3}$, Paulo Artaxo ${ }^{4}$, Karla M. Longo ${ }^{5, a}$, \\ Jane P. Mulcahy ${ }^{1}$, Graham W. Mann ${ }^{6}$, Mohit Dalvi ${ }^{1}$, and Nicolas Bellouin ${ }^{7}$ \\ ${ }^{1}$ Met Office, Exeter, UK \\ ${ }^{2}$ CEMPS, University of Exeter, Exeter, UK \\ ${ }^{3}$ Centre for Atmospheric Science, University of Manchester, Manchester, UK \\ ${ }^{4}$ Physics Institute, University of São Paulo, São Paulo, Brazil \\ ${ }^{5}$ National Institute for Space Research (INPE), São José dos Campos, Brazil \\ ${ }^{6}$ National Centre for Atmospheric Science, School of Earth and Environment, University of Leeds, Leeds, UK \\ ${ }^{7}$ Department of Meteorology, University of Reading, Reading, UK \\ anow at: NASA Goddard Space Flight Center and USRA/GESTAR, Greenbelt, MD, USA
}

Correspondence to: Ben T. Johnson (ben.johnson@metoffice.gov.uk)

Received: 24 May 2016 - Published in Atmos. Chem. Phys. Discuss.: 6 June 2016

Revised: 14 October 2016 - Accepted: 20 October 2016 - Published: 24 November 2016

\begin{abstract}
We present observations of biomass burning aerosol from the South American Biomass Burning Analysis (SAMBBA) and other measurement campaigns, and use these to evaluate the representation of biomass burning aerosol properties and processes in a state-of-the-art climate model. The evaluation includes detailed comparisons with aircraft and ground data, along with remote sensing observations from MODIS and AERONET. We demonstrate several improvements to aerosol properties following the implementation of the Global Model for Aerosol Processes (GLOMAP-mode) modal aerosol scheme in the HadGEM3 climate model. This predicts the particle size distribution, composition, and optical properties, giving increased accuracy in the representation of aerosol properties and physical-chemical processes over the Coupled Largescale Aerosol Scheme for Simulations in Climate Models (CLASSIC) bulk aerosol scheme previously used in HadGEM2. Although both models give similar regional distributions of carbonaceous aerosol mass and aerosol optical depth (AOD), GLOMAP-mode is better able to capture the observed size distribution, single scattering albedo, and Ångström exponent across different tropical biomass burning source regions. Both aerosol schemes overestimate the uptake of water compared to recent observations, CLAS-
\end{abstract}

SIC more so than GLOMAP-mode, leading to a likely overestimation of aerosol scattering, AOD, and single scattering albedo at high relative humidity. Observed aerosol vertical distributions were well captured when biomass burning aerosol emissions were injected uniformly from the surface to $3 \mathrm{~km}$. Finally, good agreement between observed and modelled AOD was gained only after scaling up GFED3 emissions by a factor of 1.6 for CLASSIC and 2.0 for GLOMAPmode. We attribute this difference in scaling factor mainly to different assumptions for the water uptake and growth of aerosol mass during ageing via oxidation and condensation of organics. We also note that similar agreement with observed AOD could have been achieved with lower scaling factors if the ratio of organic carbon to primary organic matter was increased in the models toward the upper range of observed values. Improved knowledge from measurements is required to reduce uncertainties in emission ratios for black carbon and organic carbon, and the ratio of organic carbon to primary organic matter for primary emissions from biomass burning. 


\section{Introduction}

Biomass burning is a major source of tropospheric aerosol globally (van der Werf et al., 2010) and dominates the aerosol burden in many tropical regions. Carbonaceous aerosols are produced from open burning of vegetation, including both wildfires and managed fires for clearing forest, pasture, and arable land. These aerosols have a wide range of impacts (Voulgarakis and Field, 2015), including short-term influences on local and regional weather (e.g. Kolusu et al., 2015) and significant impacts on regional air quality and human health (Johnston et al., 2012; Reddington et al., 2015). They also have a significant role in climate change as they affect the global energy budget in a number of ways (e.g. Boucher et al., 2013; Bauer and Menon, 2012; Haywood and Boucher, 2000).

The aerosols emitted from biomass burning (BB) are composed primarily of organic carbon and black carbon and they both scatter and absorb solar radiation in the atmosphere. Such aerosol-radiation interactions lead to large reductions of surface insolation and significant radiative heating of the atmosphere (Ramanathan and Carmichael, 2008; Johnson et al., 2008a; Malavelle et al., 2011; Milton et al., 2008). These effects may suppress the hydrological cycle by stabilizing the lower troposphere, although strong absorption can in some cases enhance precipitation regionally by increasing low-level convergence (Wu et al., 2013; Ramanathan et al., 2001; Lau et al., 2008; Randles et al., 2008). The enhancement of particulate numbers by BB can also increase the concentration of cloud condensation nuclei modifying cloud microphysical properties (Spracklen et al., 2011). This can brighten clouds (Twomey, 1974) and modelling studies have also shown that smoke (aerosol) from BB can delay the onset of precipitation and influence the evolution of convective clouds (Andreae et al., 2004; Feingold et al., 2001). The localized heating associated with absorption of solar radiation by the emitted particles can also suppress convection and change regional cloud cover via the semi-direct aerosol effect (Koren et al., 2008; Tosca et al., 2014).

Quantifying the impact of BB aerosol emissions on the global radiation budget and climate is therefore difficult, with many competing effects and sources of uncertainty (Ten Hoeve et al., 2012; Ward et al., 2012). Recent assessments suggest that on a global basis, changes in the top of the atmosphere (TOA) radiation budget resulting from increased scattering due to aerosol emitted from BB are approximately cancelled by increased absorption by the aerosol (Myhre et al., 2013; Shindell et al., 2013; Bellouin et al., 2013). However, the extent to which scattering and absorption compensate varies regionally, as it depends on many factors, including the surface albedo, cloud cover, and the optical properties of the aerosol. In particular, the single scattering albedo (e.g. Myhre et al., 2008) and the vertical distribution of the absorbing aerosol relative to clouds (e.g. Samset et al., 2013) have a strong influence on this potential balance. Absorption depends mainly on the black carbon content of the aerosol, but a significant contribution in the UV and to a lesser extent visible spectra can come from organics, i.e. brown carbon (Saleh et al., 2014).

Overall, BB aerosol emissions are estimated to lead to a global mean negative effective radiative forcing (ERF) as aerosol-cloud interactions in models are shown to exert a negative forcing that outweighs any small positive forcing from aerosol-radiation interactions. This is expected to have a cooling influence on global climate, but the ERF and global temperature responses are estimated to be relatively small, compared to those from sulfates or black carbon from fossil fuel combustion (Jones et al., 2007; Shindell et al., 2013). Nevertheless, increases in aerosol due to BB have potentially important impacts on regional climates, via changes in atmospheric circulation and shifts in precipitation (Tosca et al., 2010, 2013; Ott et al., 2010; Zhang et al., 2009; Jones et al., 2007).

Recent studies have also highlighted more complex Earthsystem interactions associated with BB emissions. By scattering solar radiation and increasing the ratio of diffuse to direct radiation at the surface, aerosol can enhance photosynthesis over tropical forests, increasing net primary productivity (NPP) and carbon uptake (Rap et al., 2015; Mercado et al., 2009). On the other hand, tropospheric ozone produced due to NOx emissions from fires can damage plants, reducing NPP (Pacifico et al., 2015). Mao et al. (2013) also showed that emission of aerosol and trace gases from BB led to increases in global tropospheric ozone and methane lifetime. In their study this led to a positive radiative forcing that offset the negative radiative forcing from the sum of aerosolradiation and aerosol-cloud interaction effects.

Quantifying these wide-ranging impacts of $\mathrm{BB}$ on climate, air quality, and the Earth system relies on the accurate representation of BB processes and aerosol properties in global models. It is therefore important to evaluate their simulation in models with observations to reduce inherent biases and identify priorities for future improvements to emissions, processes, and techniques used to represent aerosol properties. The properties of aerosols in BB dominated air masses have been investigated during a number of field experiments (e.g. Kaufman et al., 1998; Swap et al., 2002; Haywood et al., 2008), and reviewed by Reid et al. (2005a, b) and Martin et al. (2010). A new set of observations is now available from the South American Biomass Burning Analysis (SAMBBA), a field campaign that took place in Brazil during 14 September-4 October 2012. The measurement campaign was a joint UK-Brazil project led by the Met Office and NERC, in collaboration with the National Institute of Space Studies in Brazil (INPE) and the University of São Paulo (USP) in Brazil. The campaign involved the UK Facility for Airborne Atmospheric Measurements (FAAM) BAe-146 atmospheric research aircraft coordinated with a range of ground-based observations (Allan et al., 2014; Brito et al., 2014; Marenco et al., 2016). The air- 
borne campaign comprised 20 flights investigating aerosol properties, atmospheric chemistry, clouds, meteorology, and the radiation budget over Amazonia. The flights provided intensive measurement of aerosols across Amazonia, including aerosol dominated by BB emissions.

In this study we combined the observations from SAMBBA with those from previous campaigns and from long-term remote sensing observations (MODIS, AERONET) to evaluate the representation of biomass burning aerosol (BBA) in a state-of-the-art global climate model, the Hadley Centre Global Environment Model version 3 (HadGEM3). We evaluate two aerosol schemes: (i) the massbased Coupled Large-scale Aerosol Scheme for Simulations in Climate Models (CLASSIC) aerosol scheme and (ii) the Global Model for Aerosol Processes (GLOMAPmode) microphysical scheme. CLASSIC was previously used in HadGEM2-ES for CMIP5 (Bellouin et al., 2011) and in this study is used within HadGEM3. GLOMAPmode has been implemented more recently in the Met Office Unified Model and is available in HadGEM3 (e.g. Bellouin et al., 2013) (in some publications configurations of HadGEM3 that include GLOMAP-mode have been referred to as HadGEM-UKCA). The study focuses on aerosol properties important in simulating aerosol-radiation interactions, including the global distribution of aerosol and their physical, chemical, and optical properties. The study provides an assessment of the influence of biomass burning on aerosol properties, as simulated by each scheme, and assesses some of the assumptions commonly used to represent BB aerosol emissions and aerosol processes in global models.

\section{Methods}

\subsection{HadGEM3 model configuration}

This work uses global simulations of the Met Office Unified Model (MetUM) within the HadGEM3 framework (Hewitt et al., 2011). The scientific configuration of the physical model was from the Global Atmosphere 7 (GA7) configuration and our simulations ran with a resolution of $\mathrm{N} 96\left(1.25^{\circ} \times 1.875^{\circ}\right)$ and 85 vertical levels. Sea surface temperatures and sea ice were prescribed using reanalysed daily varying fields for the period 2002-2011 based on the methodology of Reynolds et al. (2007) (as used in the Atmosphere Model Intercomparison Project). The atmospheric circulation was free-running, including aerosol-radiative effects from either CLASSIC or GLOMAP-mode. The atmospheric physics configuration includes some updates to atmospheric processes over previous configurations presented in Williams et al. (2015) and Walters et al. (2014). The main update affecting this study is the implementation of the GLOMAP-mode (Mann et al., 2010) modal aerosol scheme. The implementation of GLOMAPmode in the MetUM took place as part of the UKCA (United Kingdom Chemistry and Aerosol) project along with sev- eral alternative atmospheric chemistry schemes. In this study we use an offline-chemistry configuration where concentrations of gas-phase chemical species [ozone $\left(\mathrm{O}_{3}\right)$, hydrogen peroxide $\left(\mathrm{H}_{2} \mathrm{O}_{2}\right)$, and the hydroxyl $(\mathrm{OH})$, nitrate $\left(\mathrm{NO}_{3}\right)$ and hydroperoxyl $\left(\mathrm{HO}_{2}\right)$ radicals] required for the oxidation of aerosol precursor species are provided as monthly mean climatologies. The climatology of oxidants was generated from a previous 20-year simulation that included online gas-phase atmospheric chemistry using the UKCA combined tropospheric and stratospheric chemistry scheme (O'Connor et al., 2014; Morgenstern et al., 2009). For this study a parallel simulation was also run with the same model configuration except that aerosols were simulated by the CLASSIC aerosol scheme. CLASSIC was the aerosol scheme used in HadGEM2, including Hadley Centre contributions to the fifth Coupled Model Intercomparison Project (CMIP5) (Bellouin et al., 2011). CLASSIC used a climatology of oxidants generated separately from an earlier simulation. For both aerosol schemes fire emissions of BBA were taken from the Global Fire Emission dataset (GFED) version 3.1 (van der Werf et al., 2010). We use monthly mean emissions averaged over the period 2002-2011. Details of how these were implemented are given in Sect. 2.3. Anthropogenic emissions of $\mathrm{SO}_{2}$ and carbonaceous aerosol (from fossil fuel and bio-fuel) for both aerosol schemes were based on the 10-year average emissions from 2002 to 2011. These data were provided by MACC/CityZEN (via ECCAD-Ether at http://eccad.sedoo.fr) that interpolates across this time frame using historical emissions for 2000 from ACCMIP (Lamarque et al., 2010) and emissions for 2005 and 2010 from the RCP8.5 scenario (Granier et al., 2011; Diehl et al., 2012). However, we keep annual emissions constant at the 20022011 mean rate. Volcanic degassing emissions of $\mathrm{SO}_{2}$ were taken from Andres and Kasgnoc (1998). Emissions of dimethyl sulfide (DMS) were calculated from the Kettle et al. (1999) ocean DMS climatology with the Liss and Merlivat (1986) surface-exchange parameterization. Stratospheric aerosol was represented via the climatology from Cusack et al. (1998). Nitrate aerosols were not included in this study.

\subsection{Representation of aerosols}

\subsubsection{CLASSIC}

CLASSIC is a mass-based or "bulk" aerosol scheme that represents a range of aerosol species (sulfate, fossil-fuel soot, fossil-fuel organic carbon, BBA, sea salt, and mineral dust) as separate externally mixed species with specified physical and optical properties. A full description of the scheme is available in the appendix of Bellouin et al. (2011). CLASSIC includes a representation of the sulfur cycle for the gasphase and aqueous-phase production of sulfate aerosol. Carbonaceous aerosols are represented as three separate species depending on their emission source (soot, fossil-fuel organic carbon, BBA). Each has different assumptions regard- 
ing their physical, chemical, and optical properties. The representation of the BBA species is based on the aircraft observations of Haywood et al. (2003) and Abel et al. (2003) obtained over southern Africa during SAFARI-2000 and is described in more detail below. Mineral dust is simulated by the six-bin scheme of Woodward (2001), with modifications in Woodward (2011). CLASSIC uses a diagnostic scheme for wind-driven sea salt, i.e. sea salt aerosol is not transported but instead is diagnosed locally over ocean points as a function of wind speed and with a prescribed scale height in the vertical (see Bellouin et al., 2011; Jones et al., 2001). Secondary organic aerosol (SOA) is not modelled explicitly by CLASSIC, but the contribution to AOD and radiative effects is included using an offline climatology. The SOA climatology is provided by the UK Met Office chemistry transport model (STOCHEM) (Derwent et al., 2003) based on the emission of isoprene from biogenic sources.

The BBA species includes a fresh mode to represent the primary particles and an aged mode to represent the aerosols after chemical ageing and growth. A third tracer is used to track the mass of in-cloud BBA particles that are either lost via wet deposition or return to the aged BBA mode as rain water is lost via evaporation. The size distribution for each mode is represented by a single log-normal with a standard deviation of 1.3 and a mean diameter of $0.2 \mu \mathrm{m}$ for the fresh mode and $0.24 \mu \mathrm{m}$ for the aged mode. The total aerosol mass emitted into the fresh mode is taken as the sum of BC and OC from GFED, but the model makes its own assumptions regarding the proportion of $\mathrm{BC}$ and $\mathrm{OC}$ in each $\mathrm{BBA}$ mode. Each BBA mode is assumed to be an internal mixture of black carbon (BC) and organic carbon (OC) with an organic carbon mass fraction of $91.5 \%$ for the fresh mode and $94.6 \%$ for the aged and in-cloud modes. The ageing process occurs on a $6 \mathrm{~h}$ e-folding timescale and during the transfer from the fresh to aged mode the aerosol mass is increased by a factor of 1.62. This representation of aerosol ageing is based on the evolution of aerosol properties in a large smoke plume observed during SAFARI-2000 (Abel et al., 2003). Optical properties are calculated from Mie theory with the refractive index (RI) computed as the volume-weighted average of the $\mathrm{BC}$ and $\mathrm{OC}$ components assuming an aerosol mass density of $1.35 \mathrm{~g} \mathrm{~cm}^{-3}$ for the $\mathrm{OC}$ and $1.7 \mathrm{~g} \mathrm{~cm}^{-3}$ for the $\mathrm{BC}$. The RI of the BC component is based on WCP (1983) (1.75$0.44 i$ at $550 \mathrm{~nm}$ ) and the RI of the OC component is assumed to be $1.53-0.0 i$ across the solar spectrum. This gives an RI of 1.54-0.025i for the fresh mode and 1.54-0.018i for the aged mode, in the mid-visible $(550 \mathrm{~nm})$. Both species are hygroscopic with empirical growth curves from Magi and Hobbs (2003) (Sect. 3.5).

\subsubsection{GLOMAP-mode}

The GLOMAP-mode scheme (Mann et al., 2010) has an entirely different modelling philosophy to CLASSIC, being an aerosol microphysics scheme including a size-resolved representation of the key processes which alter the particle physical and chemical properties during its lifecycle (e.g. Mann et al., 2014). The configuration of GLOMAPmode in this study (GA7) includes four soluble modes (nucleation, Aitken, accumulation, coarse) and one insoluble Aitken mode, and includes the components of sulfate, particulate organic matter, black carbon, and sea salt. Aerosol particles within any given mode are assumed to be an internal mixture of the chemical constituents in that mode. Particles within a mode can grow by condensation and coagulation. Aerosol mass and number can also be transferred from smaller to larger modes, either via coagulation between the modes or as the diameter of particles within a mode exceeds the specified limit for that mode (Mann et al., 2010). Insoluble Aitken particles also age as sulfuric acid and oxidized organic vapours condense onto them and the aerosols are transferred to the Aitken soluble mode when the coating exceeds 10 mono-layers. Although GLOMAP-mode generally treats mineral dust within the modal framework in the same way as other aerosol components, in the runs here, this modal representation for mineral dust was not used. Instead, for the GA7 configuration of the atmospheric model applied here, the existing UM bin-resolved dust scheme (Woodward, 2001, 2011) was used to transport dust (and apply its radiative effects) alongside the GLOMAP representation for other components (as in Bellouin et al., 2013). The simulation with GLOMAP-mode included primary aerosol emissions from biomass burning, bio-fuel and fossil fuel combustion sources, interactive sea spray emissions, and sub-grid sulfate particle formation (so-called "primary sulfate"), assumed to be $2.5 \%$ of emitted $\mathrm{SO}_{2}$. The scheme explicitly represents the secondary aerosol particle source from binary nucleation of sulfuric acid vapour and water vapour applying the parameterization of Kulmala et al. (1998). The transfer of secondary organic aerosol (SOA) mass to the particle phase occurs following the oxidation of emitted biogenic volatile organic compounds (bVOCs), chemically producing a zero vapour pressure gas-phase species "SEC_ORG" which then condenses onto existing particles (increasing the OA mass in each mode). In these simulations, no anthropogenic SOA was produced, with the only SOA-producing bVOC being a lumped monoterpene species "MONOTER" produced by emissions from Guenther et al. (1995). The chemical production of SEC_ORG from MONOTER proceeds via reaction with $\mathrm{OH}, \mathrm{NO}_{3}$, and $\mathrm{O}_{3}$, with rates given by oxidation rates for alpha-pinene, and assuming a $26 \%$ molar yield to the particle phase. The $26 \%$ value increased from the $13 \%$ used by Bellouin et al. (2013) to account for missing SOA from isoprene.

Aerosol particle emissions from biomass burning are assumed to have an initial (emitted) size distribution given by a single log-normal mode with a geometric mean diameter of $0.15 \mu \mathrm{m}$ and a geometric standard deviation of 1.59 , as used by Stier et al. (2005) and consistent with the range of log-normal parameters fitted to BB aerosol size distributions 
in Fig. C2 of Dentener et al. (2006). The ratio of BC to OC varies interactively in GLOMAP-mode depending on mixing of these components from the range of sources mentioned above. There is currently no representation of the SOA from semi-volatile VOCs partitioning into the aerosol particle phase. In GLOMAP-mode, the BC component of carbonaceous particles is always assumed hydrophobic, whereas the POM component is assumed to be hydrophobic in insoluble particles and hydrophilic in soluble particles. Further details on the hygroscopic growth are given in Sect. 3.5. Aerosol optical properties are derived for each mode as a function of aerosol mode diameter and RI using look-up-tables with precomputed results from Mie theory. For these the RI is computed by volume-weighted averages depending on the mixture of components within any given mode. The RI of the $\mathrm{BC}$ component, as in CLASSIC, is based on WCP (1983) and the OC component is assumed to be non-absorbing with an RI of $1.5-0.0 i$ across the solar spectrum. Aerosol mass density for $\mathrm{BC}$ and $\mathrm{OC}$ are both assumed to be $1.5 \mathrm{~g} \mathrm{~cm}^{-3}$.

\subsection{Biomass burning aerosol emissions and scaling factors}

\subsubsection{Global emission scaling factor}

Fire emissions of BBA were taken from the Global Fire Emission Dataset (GFED) version 3.1 (van der Werf et al., 2010). Preliminary simulations with GFED3.1 emissions led to large underestimates in modelled aerosol mass and AOD over tropical BB regions. Therefore, we apply global scaling factors of 1.6 for CLASSIC and 2.0 for GLOMAP-mode (Table 1) to increase the total $\mathrm{BB}$ aerosol emissions to give better agreement between modelled and observed mid-visible AOD (see Sect. 3.1). These scaling factors were not calculated precisely, but were found to give good overall correspondence between modelled and observed peak AODs (from AERONET and MODIS) over continental BB source regions in the tropics, and a consistent AOD contribution from BB emissions in CLASSIC and GLOMAP-mode over the BB source regions. Other modelling studies have also found it necessary to apply global scaling factors to increase aerosol emissions from BB sources to gain realistic AOD and/or particulate mass concentrations (Kaiser et al., 2012; Marlier et al., 2013; Petrenko et al., 2012; Tosca et al., 2013; Archer-Nicholls et al., 2016; Kolusu et al., 2015; Reddington et al., 2016). Note that observed AODs are also used to derive biome specific or spatially varying scaling factors in some top-down emission estimation methods such as the Quick Fire Emission Dataset (QFED; Darmenov and da Silva, 2015) and the Fire Energetics and Emissions Research (FEER) (Ichoku and Ellison, 2014), and these lead to global total particulate matter emissions approximately 2-3 times greater than GFED3.1 (Ichoku and Ellison, 2014). However, we acknowledge that the discrepancy between modelled and observed AOD (prior to emission scaling) could be due to other biases or missing processes in the models.

In the CLASSIC simulation the global scaling factor of 1.6 (Table 1) was applied to the total mass emitted into the BBA tracer. For GLOMAP-mode a factor of 2.0 was applied to the $\mathrm{BB}$ emissions of aerosol mass (both the OC and BC components) and number. The scaling used here differs between the two aerosol schemes, and the aim of doing so is to quantify the magnitude of the discrepancy between modelled and observed AOD (prior to scaling), and highlight the fact that the discrepancy depends on assumptions and processes internal to the aerosol schemes themselves. It should be noted that the scaling factors found here could be substantially reduced if the overall mass of carbonaceous aerosol was increased in the models. This could have been achieved either by increasing the ratio of organic carbon to primary organic matter (Sect. 2.3.2 below), or in the case of GLOMAP-mode by including a representation for secondary organic aerosol formation from VOCs emitted during BB (Sect. 2.3.3).

\subsubsection{Scaling of organic carbon to primary organic matter}

In this study biomass burning emissions of the organic aerosol component are derived from the $\mathrm{OC}$ flux provided by GFED3.1. As OC represents the mass of the carbon only, the contribution of other elements (principally oxygen) to the total organic aerosol mass (i.e. primary organic matter - POM) must be considered separately. In CLASSIC no scaling is applied to convert the mass of OC to POM. In GLOMAPmode OC is converted to POM assuming a POM : OC mass ratio of 1.4 (Table 1). This conversion factor of 1.4 has been broadly used in atmospheric models and was originally based on analysis of filter measurements of fresh urban emissions from the 1970s onwards (see Turpin and Lim, 2001, and references therein). More recent analyses of aerosol mass spectra (e.g. Aiken et al., 2008; Ng et al., 2010; Tiitta et al., 2014; Brito et al., 2014) and preliminary analysis of airborne data from SAMBBA indicate POM : OC ratios in the range 1.51.8 for fresh particles/near-source emissions from biomass burning. Therefore, an upward adjustment from the 1.4 conversion factor widely assumed may be warranted to more accurately simulate the aerosol mass emissions from BB. However, the observations indicate considerable variability, with aerosol age and source region with POM : OC ratios increasing to 2.0-2.3 for aged and more highly oxidized aerosol. This introduces considerable uncertainty in gauging a representative POM : OC for global models where near-source ageing may not be represented.

\subsubsection{Growth of organic aerosol component during ageing}

In CLASSIC the condensation of VOCs onto BBA is represented in a simplified manner increasing the aerosol mass 
Table 1. Biomass burning aerosol emissions: emitted particle properties and scaling factors applied.

\begin{tabular}{lccc|ccc}
\hline Aerosol scheme & \multicolumn{3}{c|}{ Emitted particle properties } & \multicolumn{3}{c}{ Scaling factors applied } \\
\cline { 2 - 7 } & $\mathrm{Dg}$ & $\sigma$ & $\mathrm{BC}:$ OC & POM : OC conversion & Ageing growth factor & Global emission scaling \\
\hline CLASSIC & 0.20 & 1.3 & 0.093 & $\mathrm{n} / \mathrm{a}$ & 1.62 & 1.6 \\
GLOMAP-mode & 0.15 & 1.59 & Variable (GFED3.1) & 1.4 & $\mathrm{n} / \mathrm{a}$ & 2.0 \\
\hline
\end{tabular}

by a factor of 1.62 (Table 1) when the fresh BB mode is converted to the aged mode. This scaling factor is based on measurements from a large plume during SAFARI-2000 (Abel et al., 2003). However, the evidence for growth of aerosol mass in BB plumes is mixed. For example, Vakkari et al. (2014) concluded that oxidation and subsequent secondary aerosol formation were important in the evolution of smoke plumes $2-4 \mathrm{~h}$ after emission. In contrast, other studies based on aircraft measurements of aerosol composition and emission ratios have shown no net mass gain, or even net loss of aerosol mass between fresh and aged plumes, despite oxidation (chemical ageing). These studies include measurements from West Africa (Capes et al., 2008), from SAMBBA (Morgan et al., 2014), and from a synthesis of the West African measurements with three other campaigns (Jolleys et al., 2012). These suggest that evaporation of organic material after initial emission outweighs or at least compensates for mass added due to secondary formation of organic aerosol. The assumed growth in CLASSIC is therefore not fully supported by recent observational analyses and is an aspect of the scheme that must be considered as we evaluate the model.

The configuration of GLOMAP-mode here does not include secondary aerosol formation from VOCs emitted by biomass burning, or the associated variation of POM : OC during chemical ageing. This is acknowledged as a potentially large source of bias that may to some extent necessitate the global emission scaling.

\subsubsection{Vertical injection height assumptions}

Smoke plumes can rise several kilometres before detraining into the atmosphere, although this depends critically on fire size/heat flux and atmospheric stability (Freitas et al., 2007). Regional assessments show that the majority of smoke plumes detrain in the boundary layer with maximum plume heights typically below $2 \mathrm{~km}$, whereas vigorous plumes from some large fires can extend into the free troposphere up to altitudes of $6 \mathrm{~km}$ or more in exceptional cases (Freitas et al., 2007; Kahn et al., 2008; Val Martin et al., 2010; Val Martin et al., 2012; Sofiev et al., 2012; Tosca et al., 2011). During SAMBBA the concentration of aerosol was generally highest in the lowest $2-3 \mathrm{~km}$ (corresponding to the maximum height of the atmospheric boundary layer) and declined rapidly with height above this (Marenco et al., 2016). Tenuous aerosol layers were frequently observed in the mid-troposphere up to altitudes of 5 or $6 \mathrm{~km}$, but given the prevalence of moist convection during SAMBBA (mainly in the western region) it was difficult to determine whether these elevated layers related to plume injection heights or were the result of vertical transport and detrainment from cumulus (in some cases pyrocumulus were also observed).

HadGEM3 does not include an explicit smoke plumerise model, but prescribes the vertical profile of emissions depending on vegetation type provided by GFED. Following recommendations from the first phase of AeroCom (see Sect. 7 and Fig. 9 of Dentener et al., 2006), fire emissions from peat fires, savannah, and woodland are assumed to have small plume rise and are emitted at the lowest model level, allowing sub-grid-scale turbulence to mix these through the boundary layer. Emissions from forest and tropical deforestation fires are assumed to have more significant plume rise and are injected uniformly from the surface to an assumed maximum injection height of $3 \mathrm{~km}$. These injection height assumptions were used identically for both the CLASSIC and GLOMAP-mode simulations to maintain consistency.

\subsection{Experimental design of simulations}

Five simulations were completed, each with a 3-month spinup followed by a 10-year run with emissions, SSTs, and sea ice based on the years 2002-2011. The main two simulations that are evaluated in this study are (i) CLASSIC aerosols with a BB emission scaling factor of 1.6 and (ii) GLOMAP-mode aerosols with a $\mathrm{BB}$ emission scaling factor of 2.0. A third simulation with GLOMAP-mode with no BB aerosol emissions was required to enable the contribution of $\mathrm{BB}$ emissions to AOD and aerosol mass to be inferred. Furthermore, to illustrate why emission scaling was necessary, we also include results in Sect. 3.1 from CLASSIC and GLOMAPmode simulations without scaling of BB emissions. Apart from these changes in the simulation of aerosols, the scientific configuration of the atmospheric model was identical in all simulations. In these simulations the atmospheric circulation was free-running (not nudged to meteorological analyses) and so a 10-year period is required to average over the interannual variability of meteorology. The selected time period 2002-2011 spans the last 10 years where GFED3.1 data were available. One advantage of selecting this time period rather than earlier years is that the GFED3.1 emissions benefit from inclusion of the burned area product from Aqua MODIS from 2002 onwards. Unfortunately, the GFED3.1 
data were not available for 2012 (the period of the SAMBBA campaign). For this reason the evaluations against aircraft campaign data in this study focus on the intrinsic properties of BBA (physical, chemical, and optical properties) that are expected to depend more on the vegetation and burning practices in the observed regions than on year-to-year variability of burned area.

\subsection{In situ observations from SAMBBA and other biomass burning campaigns}

Aircraft measurements of aerosol properties have been taken from the SAMBBA campaign that took place in Brazil during September-October 2012. As the aerosol properties differed regionally we present average properties separately for the western region (flights based from Rondonia: $7-12.5^{\circ} \mathrm{S}$, $58-65^{\circ} \mathrm{W}$ ) and eastern region (flights over Tocantins: 10 $12^{\circ} \mathrm{S}, 46.5-49^{\circ} \mathrm{W}$ ) (Fig. 1). The regional averages of aerosol particle size distribution, composition, and optical properties are based on data from straight level runs sampling the regional haze. Data sections corresponding to plume penetrations (identified from spikes in $\mathrm{CO}, \mathrm{CO}_{2}, \mathrm{BC}$, and aerosol scattering) were filtered out prior to averaging. An overview of the flights and full details of instrumentation are provided in Darbyshire and Johnson (2012) and data processing methods will be described in Darbyshire et al. (2016). Aircraft measurements have also been taken from the Dust and Biomass Burning Experiment (DABEX) over West Africa $\left(7-15^{\circ} \mathrm{N}, 0-7^{\circ} \mathrm{E}\right.$ ) during January-February 2006 (Haywood et al., 2008; Johnson et al., 2008b) and from the Met Research Flight C130 aircraft during the Southern African Regional Science Initiative (SAFARI-2000) in September 2000

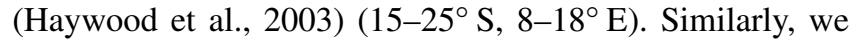
use the regional averages for aged regional haze provided from these campaigns. The boxes in Fig. 1 indicate the regions where the flights took place and where model data were averaged.

Common to each of the aircraft datasets is the use of a wing-mounted Passive Cavity Aerosol Spectrometer Probe (PCASP) to measure aerosol particle size distributions, a TSI three-wavelength nephelometer $(440,550,700 \mathrm{~nm})$ to measure aerosol scattering, and a single-wavelength Particle Soot Absorption Photometer (523 nm) to measure aerosol absorption and the SSA (when combined with the nephelometer). During SAMBBA the PCASP suffered some instrument/electronic processing errors after the first four flights (B731-734). Therefore, stringent quality checks on the data were employed to filter out affected data. After this, approximately $16 \mathrm{~h}$ of PCASP data were available from eight flights, with $75 \%$ of this from the first four flights (B731734) that focussed mainly on sampling aerosol dominated by biomass burning emissions. During SAMBBA, PCASP measurements of aerosol size distribution were supplemented by a GRIMM Optical Particle Counter (OPC) and a TSI Scanning Mobility Particle Sizer (SMPS). The aerosol composi-
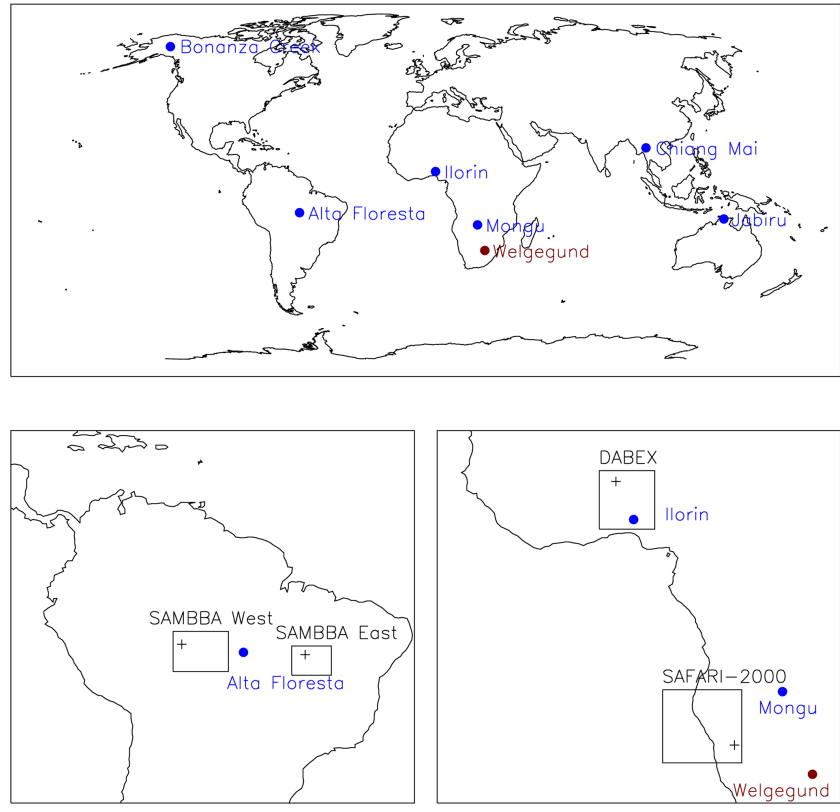

Figure 1. Maps showing the location of AERONET sites (blue), the Welgegund ground station, and the averaging boxes used corresponding to the flight regions from SAMBBA (West and East), DABEX, and SAFARI-2000. Plus symbols indicate the locations of the main airbases used for the flights: Porto Velho for SAMBBA West, Palmas for SAMBBA East, Niamey for DABEX, and Windhoek for SAFARI-2000.

tion was also measured during SAMBBA and DABEX. In both cases the sulfate mass and the organic aerosol (OA) (i.e. total carbonaceous aerosol mass from POM and secondary organic aerosol) were measured by an Aerodyne Aerosol Mass Spectrometer (Capes et al., 2008; Allan et al., 2014). During SAMBBA the BC mass was estimated from a Single Particle Soot Photometer and during DABEX the BC mass was estimated from the PSAP assuming a mass absorption coefficient of $12 \mathrm{~m}^{2} \mathrm{~g}^{-1}$. For each flight campaign the aircraft observations have been averaged over all available measurements taken in biomass burning conditions to provide campaign mean BB aerosol properties. Ground-based observations of aerosol composition have also been used based on data presented in Tiitta et al. (2014) from the Welgegund station in South Africa (Fig. 1). They used an Aerosol Chemical Speciation Monitor to measure OA and sulfate and a Multi-Angle Absorption Photometer to measure BC assuming a mass absorption coefficient of $6.6 \mathrm{~m}^{2} \mathrm{~g}^{-1}$. We take an average composition from their measurements in September 2010 .

\subsection{Remote sensing observations}

MODIS AOD retrievals have been obtained from the Aqua satellite. In this study we use monthly mean level 3 MYD08_M3 data products and to aid the evaluation we in- 
clude the AOD products from both collection 5.1 and collection 6. In the case of collection 5.1 the dark-target (Levy et al., 2007, 2010) and ocean algorithms (Remer et al., 2005) have been used where coverage is available, and the Deep Blue algorithm (Hsu et al., 2004, 2006) has been used for pixels over bright land surfaces where dark-target retrievals were not available. For collection 6 the merged product (Sayer et al., 2014) has been used that combines retrievals from all three algorithms and includes various refinements to each (Sayer et al., 2013; Levy et al., 2013). Terra products were not included as drift in the calibration of MODIS Terra in the later years of our observation window may have affected the retrieved AODs (Polashenski et al., 2015). The monthly mean data have been averaged over the period 2003-2012 to create long-term monthly means.

AERONET data have also been used for direct sun retrievals of AOD and for inversion products of aerosol size distribution and optical properties. Six sites with strong biomass burning influence were selected for use in this study: Alta Floresta (Brazil), Mongu (Zambia), Ilorin (Nigeria), Chiang Mai (Thailand), Jaribu (northern Australia), and Bonanza Creek (Alaska) (Fig. 1). We used monthly mean products from the version 2 algorithm (Dubovik and King, 2000; Dubovik et al., 2006) and used level 2 products in all cases except Chiang Mai, where level 1.5 data were used as level 2 data coverage was limited. Level 1.5 data are not fully cloudscreen and calibrated, and so may not be as reliable. Longterm monthly mean averages were calculated for 2002-2011.

\subsection{Averaging methods}

The aircraft in situ observations presented in this study have been averaged over all available measurements in biomass burning dominated conditions in each campaign or campaign sub-region, to provide representative "campaign-mean" values. The data averaging methods for SAMBBA will be described in more detail in Darbyshire et al. (2016). The DABEX campaign means are taken from the observations of aged aerosol layers in Johnson et al. (2008b). SAFARI2000 campaign means are based on a compilation of aged aerosol measurements, as detailed in Haywood et al. (2003). Inevitably, aircraft flight patterns do not provide unbiased spatial and temporal sampling of the atmosphere and tend to favour sampling aerosol layers with medium-high aerosol loadings. However, by averaging over large volumes of data focussed on regional sampling, these aircraft datasets can provide useful constraints on the physical, chemical, and optical properties of the aged aerosol. Wherever comparisons are made with model data, they are based on the 10-year (long-term) monthly mean output from the models (September for SAMBBA and SAFARI-2000, January for DABEX). For comparison with aircraft measurements, the model data have been averaged over the latitude and longitude ranges of the relevant flight regions (boxes in Fig. 1) and over 0$5 \mathrm{~km}$, the typical altitude range of the observed aerosol lay- ers. For the comparison with Welgegund surface measurements, model data are taken from the lowest model level of the grid box co-located with the site and for September, corresponding to the peak of the BB season in southern Africa. For comparisons with AERONET the 10-year (long-term) monthly mean model output is selected for the gridbox colocated with the AERONET site and averaged vertically to provide column-mean aerosol properties. For MODIS the level 3 data have been further averaged to generate 10-year (long-term) monthly mean AODs at the native resolution of the atmospheric model. These are compared against the longterm mean model values without any sub-sampling of the model data on observation space-time points. Sampling biases that may arise due to the lack of sub-sampling are discussed in Sect. 3.1.

\section{Evaluation of CLASSIC and GLOMAP-mode with observations}

\subsection{Aerosol optical depth}

\subsubsection{Global AOD evaluation with MODIS}

Figure 2 assesses the contribution of biomass burning to annual mean aerosol optical depth (AOD) at the global scale. Figure $2 \mathrm{a}-\mathrm{d}$ show the results from the scaled simulations where the BB aerosol emissions scaling factors described in Sect. 2.3.1 have been applied. For CLASSIC the contribution of $\mathrm{BB}$ emissions to the total AOD (hereafter BBAOD) is straightforward as carbonaceous aerosols originating from biomass burning emissions are represented as separate (externally mixed) species in the model (Fig. 2a). For GLOMAP-mode, aerosols from different sources are internally mixed and so BBAOD is estimated as the difference in AOD between a simulation including BB emissions and one without (Fig. 2b). To aid the evaluation, the annual mean AODs from MODIS Aqua collections 5 and 6 are shown in Fig. $2 \mathrm{~g}$ and h. Finally, results are shown (Fig. $2 \mathrm{~g}$ and h) for the simulations where the BB aerosol emission scaling factors described in Sect. 2.3.1 were not applied.

The results show that biomass burning dominates the annual mean AOD over South America and central to southern Africa, even though BB emissions are highly seasonal in these regions. Biomass burning also makes strong contributions to annual mean AOD in parts of Indonesia, Southeast Asia, and northern Australia and to a lesser extent the boreal forests of North America and north-eastern Asia. Globally BBA emissions account for $10 \%$ of the total AOD in the scaled CLASSIC simulation and $12 \%$ in the scaled GLOMAP-mode simulation. The spatial distributions of BBAODs are very similar in both models, which is not surprising since they are driven by the same physical model and emission dataset. The magnitude of BBAOD is also very similar in both models as BB aerosol emissions were scaled sep- 
(a) CLASSIC scaled BBAOD

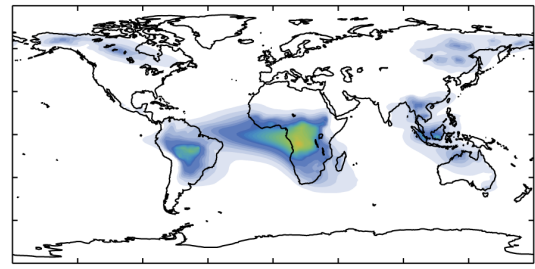

Mean: 0.014

(c) CLASSIC unscaled AOD

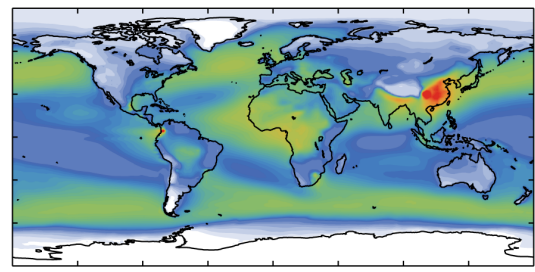

Mean: 0.142

(e) CLASSIC scaled AOD

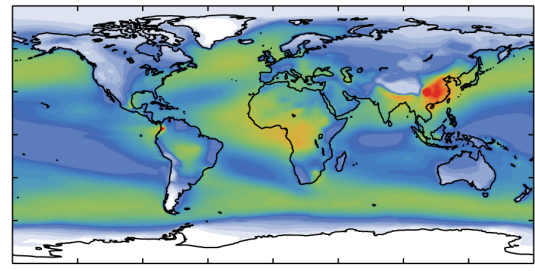

Mean: 0.147

(g) MODIS C5, 2003-2012

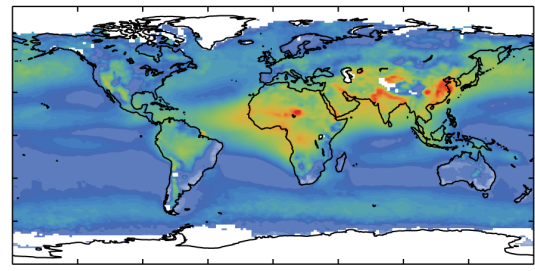

Mean: 0.155

\section{(b) GLOMAP-mode scaled BBAOD}

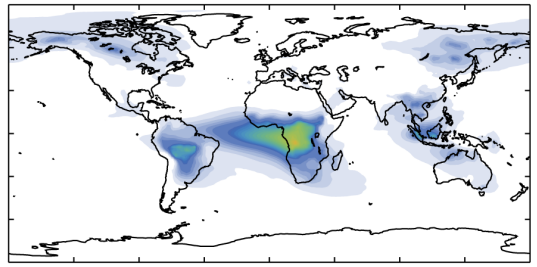

Mean: 0.016

(d) GLOMAP-mode unscaled AOD

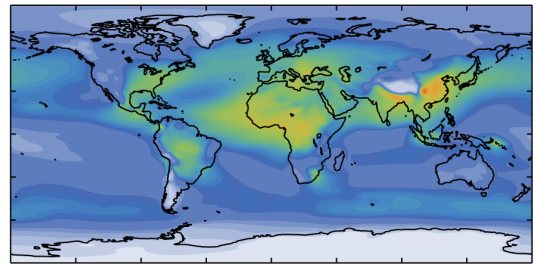

Mean: 0.125

(f) GLOMAP-mode scaled AOD

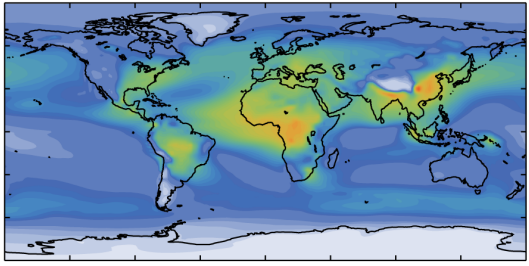

Mean: 0.133

(h) MODIS C6, 2003-2012

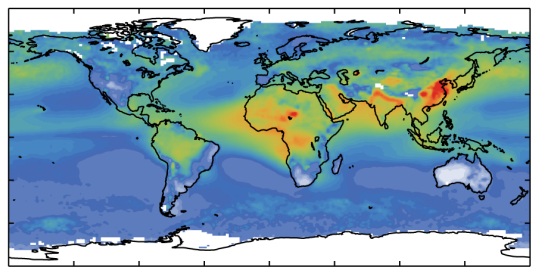

Mean: 0.162

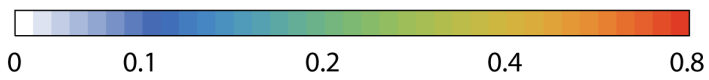

Figure 2. Decadal mean AOD at $550 \mathrm{~nm}$. Panels include (a, b) BB AOD, the contribution of BBA emissions to the total AOD in the standard (scaled) simulations; (c, d) unscaled model AODs are from simulations that did not include scaling of BB aerosol emissions; (e, f) model AOD from the standard (scaled) simulations; (g, h) MODIS data from Aqua collections 5 and 6, averaged from 2003 to 2012. Model means from 2002 to 2011. Missing data values from MODIS are plotted as white.

arately in each model to ensure the modelled AOD approximately matched MODIS and AERONET AODs observed over the main $\mathrm{BB}$ source regions during peak $\mathrm{BB}$ months where $\mathrm{BB}$ was the dominant contributor to modelled AOD.

The impact of the BB aerosol emission scaling factors is shown by comparing the total modelled AOD from scaled and unscaled simulations. The emission scaling factors have a relatively modest impact on the global distribution of AOD when assessed on an annual mean basis. This is due to the highly seasonal nature of BB emissions. Nevertheless, even in annual means, it is clear that AODs over tropical South America and Africa are somewhat lower than observed (from 
both MODIS collection 5 and 6) in the unscaled simulations. The scaling factors bring modelled AOD closer to the observations, although the benefit is clearer in later figures (3-5).

A wider assessment of simulated AOD from GLOMAPmode in HadGEM3/GA7 is expected in a future study, but we note from Fig. 2 that GLOMAP-mode has improved the distribution of AOD in several regions compared to simulation with CLASSIC. For instance, it has reduced the low bias over high-latitude continents (as found previously in Bellouin et al., 2013) and reduced a high bias in the Southern Ocean associated with sea salt aerosol. The AODs over the Sahara and North African Atlantic coast and Arabian Peninsula appear too low in the simulations, indicating that mineral dust emissions may have been too weak (in both cases simulated by CLASSIC). We note however that the GLOMAP-mode simulation also overestimates AOD in south-eastern Europe and eastern parts of the USA which are dominated by anthropogenic sources of sulfate. A strong caveat in these comparisons is that the modelled AOD has not been sampled with the spatial and temporal incidence of the MODIS data. Schutgens et al. (2016) showed that this can result in considerable regional biases between modelled and observed monthly and annual mean AOD. In particular, the comparison may be of limited value at high latitudes (beyond $60^{\circ} \mathrm{N}$ or $\mathrm{S}$ ) where retrievals are not possible for several months of the year (due to the solar zenith angle being too high, or due to a lack of solar illumination altogether). Some degree of sampling bias may occur in regions that are frequently overcast with cloud cover (e.g. marine stratocumulus regions including the southeastern Atlantic). The modelled AOD has however been calculated based on the clear-sky relative humidity to avoid strong humidification biases in partially cloudy grid boxes.

\subsubsection{Seasonal AOD in biomass burning regions with MODIS}

Figures 3 and 4 focus on the contribution of biomass burning to AOD in the tropical regions. Figure 3 shows the monthly mean BBAOD and AOD for September when BB emissions peak in the Southern Hemisphere and equatorial regions. Figure 4 shows the same for West African region but for January, when $\mathrm{BB}$ emissions peak in the zone $5-15^{\circ} \mathrm{N}$. As in the global picture (Fig. 2) the simulations give very similar regional distributions of BBAOD and AOD. Over the BB regions the modelled AOD is generally underestimated in the unscaled simulations compared to MODIS. In the scaled simulations total AODs agree very well with MODIS, especially over South America and Indonesia. However, some discrepancies between modelled and observed AODs remain over northern and southern parts of Africa. Firstly, the magnitude of AOD in the plume over the south-eastern Atlantic is lower in the models than in MODIS, even in the scaled simulations (Fig. 3). It is not clear whether this is due to poor model performance or biases related to limited temporal sampling by the satellite over the marine stratocumulus region (per- sonal communication, Andrew Sayer). MODIS collection 5 and collection 6 in particular show a large contrast in AOD between the plume over the ocean and the AOD over adjacent land areas of southern Africa. Secondly, in Fig. 4 the peak AOD and BBAOD in the models during January are centred over central Africa (Congo basin) rather than over the Gulf of Guinea where MODIS AOD peaks. This leads to an overestimate of modelled AOD over central Africa in the scaled simulations. Again, high cloud cover limits the spatial sampling over the Congo basin and may affect the mean AOD retrieved from MODIS. This regional bias was noted in previous modelling studies with GFED2 (Myhre et al., 2008; Johnson et al., 2008a) and may suggest there is still an underestimation in West Africa (Liousse et al., 2010) and potentially an overestimation of $\mathrm{BB}$ aerosol emissions in the Congo basin. The comparison of modelled and observed AOD over the BB regions of the Sahel (north of $10^{\circ}$ ) is less straightforward as mineral dust aerosol contributes strongly to the total AOD.

In the remainder of this study we assess results from the simulations where total BB aerosol emissions have been scaled, as described in Sect. 2.3.1.

\subsubsection{AOD comparison with AERONET}

To aid the evaluation of modelled AOD, six AERONET sites have been selected representing locations that are strongly affected by seasonal biomass burning. Once again, due to the scaling of total BB aerosol emissions, both CLASSIC and GLOMAP-mode give very similar AOD and BBAOD at these locations during peak months (Fig. 5). The seasonal cycle and peak AODs seem well captured at Alta Floresta (Amazonia) and Mongu (southern Africa). The comparison at Ilorin (West Africa) shows the model does not capture the observed seasonal cycle of AOD, with a low bias in AOD from November to April. This again suggests an underrepresentation of $\mathrm{BB}$ emissions across West Africa during Northern Hemisphere winter, although the low bias could be partly caused by a low bias in mineral dust aerosol from the Sahara. The secondary peak during June-September, which is not shown in the AERONET observations, may be due to overestimation of $\mathrm{BB}$ aerosol emissions from the Congo basin and long-range transport to West Africa. BBAOD appears to be underestimated at Chiang Mai (South-east Asia) and Jaribu (northern Australia), perhaps by a factor of 2, but slightly overestimated at Bonanza Creek (Alaska). Whilst these results give clues as to where $\mathrm{BB}$ aerosol emissions may be overestimated or underestimated, the differences between modelled and observed AOD may be affected by various other sources of uncertainty in the models and measurements. In particular, temporal sampling biases may affect the results (Schutgens et al., 2016), as we have not sampled the model data to match AERONET retrieval times. The approach we have taken is to average over 10 years of data to gain more confidence in the long-term monthly means. The standard errors in the monthly mean AODs are gener- 
(a) CLASSIC scaled BBAOD

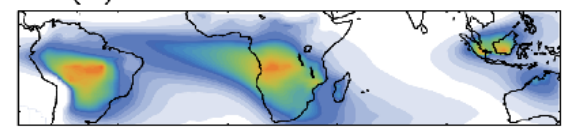

Meon: 0.070

(c) CLASSIC unscaled AOD

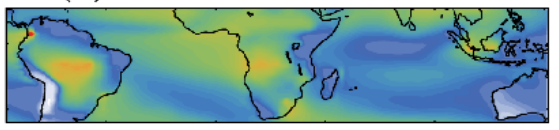

Mean: 0.168

(e) CLASSIC scaled AOD

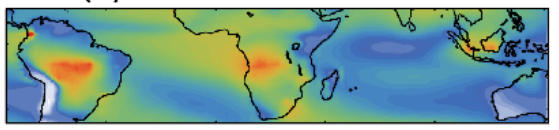

Meon: 0.194

(g) MODIS C5, 2003-2012

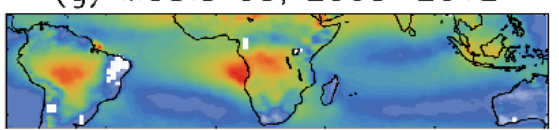

Mean: 0.194 (b) GLOMAP-mode scaled BBAOD

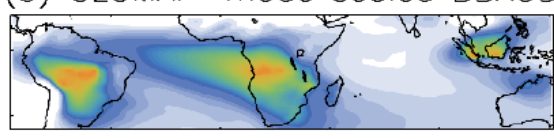

Mean: 0.075

(d) GLOMAP-mode unscaled AOD

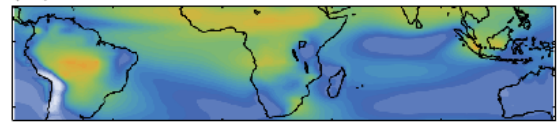

Mean: 0.167

(f) GLOMAP-mode scaled AOD

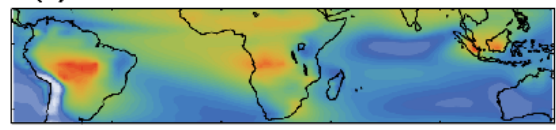

Mean: 0.204

(h) MODIS C6, 2003-2012

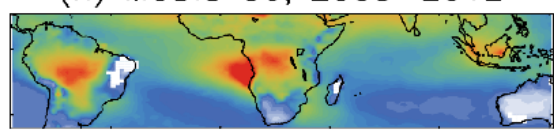

Mean: 0.212

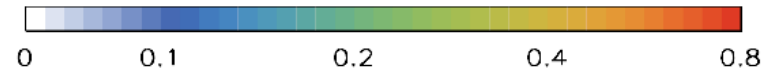

Figure 3. Same as Fig. 2 but for the month of September.

ally much smaller than the differences between observed and modelled values, indicating that our results are not strongly biased by interannual variability of either the simulated or observed AOD. The main exceptions are for August at Bonanza Creek and August-September at Alta Floresta, where the larger standard error in AERONET AOD indicates that interannual variability has a strong impact on the comparison.

\subsection{Aerosol composition}

Figure $6 \mathrm{a}$ and $\mathrm{b}$ show the column loading of fine-mode aerosol mass from the model simulations across the tropical regions during September. This is the sum of black carbon (BC), organic aerosol (OA), and sulfate (SU) from all anthropogenic and natural sources but excluding the coarse-mode contribution from GLOMAP. Clearly the fine-mode aerosol is dominated by BB sources over Africa, South America, Indonesia and northern Australia. Figure 6c-h show the relative contributions of $\mathrm{OA}, \mathrm{BC}$, and $\mathrm{SU}$ to this fine-mode mass. CLASSIC and GLOMAP-mode give very similar spatial distributions for the modelled fine-mode aerosol mass loading and composition. OA clearly dominates the finemode aerosol mass (Fig. 6c and d) in both models across most of the region shown, where $\mathrm{BB}$ emissions dominate the aerosol loading. The two exceptions are the northern edge of the domain and some stretches along the Pacific coast of South America, where sulfates dominate due to anthropogenic emissions of $\mathrm{SO}_{2}$. In Fig. 6 stipples mark grid columns where over $75 \%$ of the fine-mode aerosol mass originates from BBA emissions, based on the speciation in the CLASSIC simulation. These mark the main BB plumes from South America, Africa, and Indonesia. In GLOMAPmode where aerosols internally mix the origin of the aerosol in a grid cell can not be traced to its emission source, but it seems reasonable to assume that the grid cells strongly influenced by BB emissions in CLASSIC will also be strongly influenced by BB emissions in GLOMAP-mode given that the simulations are driven with the same emissions data and physical model configuration. The similarity in the spatial distribution of BBAOD (Figs. 2-4) and aerosol composition (Fig. 6) between the two models supports this assumption. The same areas are therefore marked with stipples in the GLOMAP-mode plots. The mean values beneath each plot indicate the mean from the stippled areas.

In the main BB plumes (marked by stippling) the CLASSIC simulations show a slightly higher mass fraction of $\mathrm{OA}$ and a slightly lower mass fraction of $\mathrm{BC}$ compared to GLOMAP-mode, with BC mass fraction averaging $5.1 \%$ in 


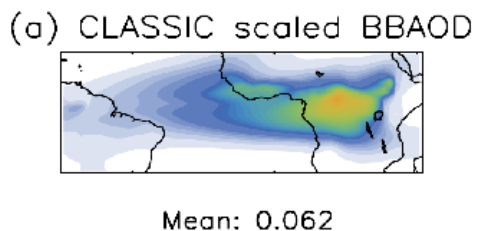

(c) CLASSIC unscaled AOD

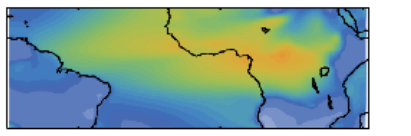

Mean: 0.194

(e) CLASSIC scaled AOD

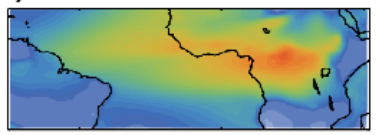

Mean: 0.217

(g) MODIS C5, 2003-2012

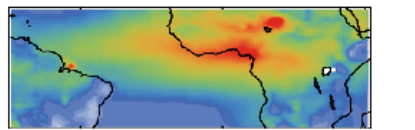

Mean: 0.235 (b) GLOMAP-mode scaled BBAOD

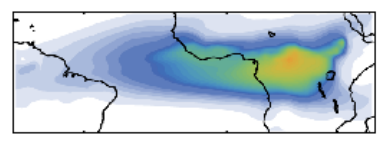

Mean: 0.061

(d) GLOMAP-mode unscaled AOD

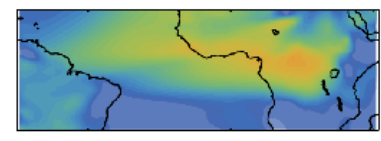

Meon: 0.188

(f) GLOMAP-mode scaled AOD

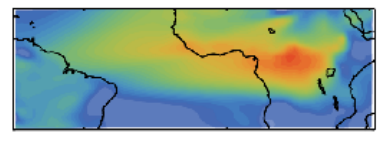

Meon: 0.219

(h) MODIS C6, 2003-2012

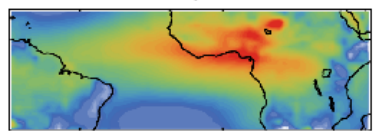

Meon: 0.254

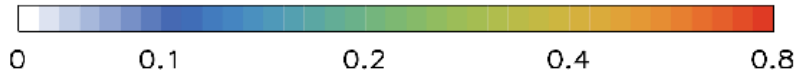

Figure 4. Same as Fig. 2 but for the month of January.

CLASSIC and $7.2 \%$ in GLOMAP-mode (Fig. 6e and f). These differences are due to differences in the way that BB composition is represented in the two schemes. In CLASSIC the ratio of BC to OA in the BBA species is specified, whereas in GLOMAP-mode it varies depending on the $\mathrm{BC}$ and $\mathrm{OC}$ mass provided by the emissions data and the OC to POM ratio assumed in the model (currently 1.4). In GLOMAP-mode secondary organic aerosol (SOA) is also added interactively via the oxidation and condensation of organic vapours from bVOCs. This decreases the BC mass fraction in north-western Amazonia compared to southeastern Amazonia and southern Africa. In CLASSIC bVOCs are not modelled explicitly, but SOA has been included using a biogenic aerosol climatology. This increases the OC mass, particularly over tropical forests, and therefore leads to a lower BC mass fraction over tropical forests compared to savannah regions. The localized peak in $\mathrm{BC}$ mass fraction near to Lake Victoria in the CLASSIC simulation is due to local anthropogenic $\mathrm{BC}$ emissions rather than $\mathrm{BB}$ emissions. This shows up less in GLOMAP-mode as the regional loading of $\mathrm{BC}$ from $\mathrm{BB}$ sources is higher.

In situ measurements from three observation campaigns have been used to evaluate the aerosol composition in the simulations. The observations include FAAM aircraft measurements from western Amazonia (Rondonia) and eastern Amazonia (Tocantins) during SAMBBA (Darbyshire et al., 2016), ground-based observations from the Welgegund measurement station in South Africa (Vakkari et al., 2014), and FAAM aircraft measurements from West Africa during DABEX (Capes et al., 2008). Figure 7 compares the observed and modelled aerosol composition by plotting the relative contributions from $\mathrm{BC}, \mathrm{OA}$, and sulfate to the total fine-mode aerosol. Nitrate, dust, and sea salt have been excluded from the analysis as nitrate was not available in the model simulations and accurate measurements of dust and sea salt were not readily available from all observation campaigns. Given that these components are neglected, we can not provide a full analysis of the aerosol composition here. The purpose of Fig. 7 is rather to examine whether the relative proportions of $\mathrm{BC}, \mathrm{OA}$, and sulfate are in line with the observational evidence (as these are the dominant contributors to fine-mode mass and fine-mode AOD in the simulations).

In all cases the fine-mode aerosol is dominated by OA with modest contributions from sulfate and generally a smaller contribution from BC. On the whole the models are able to capture the typical make-up of the aerosol and some of 

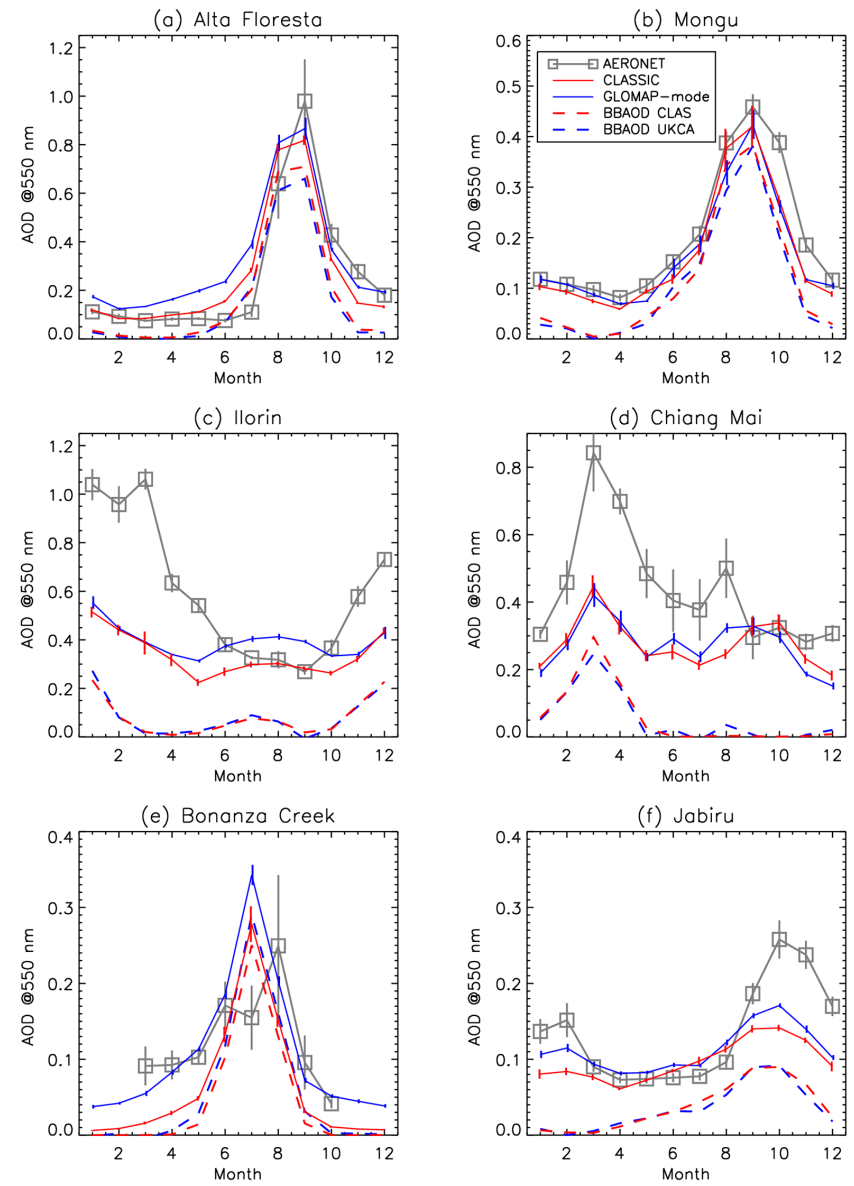

Figure 5. Monthly mean AOD at $550 \mathrm{~nm}$ from six AERONET sites (grey squares), and the same locations from GLOMAP-mode (blue) and CLASSIC (red). The contribution to AOD from BBA is shown by dashed lines. Vertical lines show \pm 1 standard error.

the variations with region, such as the higher contribution from sulfates in South Africa. GLOMAP-mode gives slightly higher BC mass fractions than CLASSIC and in general GLOMAP-mode BC mass fractions are closer to observed values. Modelling the $\mathrm{BC}$ mass fraction is of key importance for estimating absorption and the sign of direct radiative forcing. Tentatively, GLOMAP-mode therefore shows some improvement over CLASSIC, although it still appears to underestimate $\mathrm{BC}$ mass fraction relative to the measurements from West Africa, eastern Amazonia, and to a lesser extent in South Africa. However, the use of the filter-based absorption measurements in those datasets may lead to a significant overestimation of observed BC mass (Lack et al., 2008). Also, note that different mass absorption coefficients were assumed in the analyses of the DABEX $\left(12 \mathrm{~m}^{2} \mathrm{~g}^{-1}\right)$ and Welgegund $\left(6.6 \mathrm{~m}^{2} \mathrm{~g}^{-1}\right)$ observations. Unifying this assumption to an intermediate value of $10 \mathrm{~m}^{2} \mathrm{~g}^{-1}$ would change the estimated BC mass fraction to $14.1 \%$ for DABEX and $8.2 \%$ for Welgegund.

\subsection{Size distributions}

\subsubsection{Comparison with aircraft data}

Figure 8 shows the size distributions from the models and in situ observations from the three aircraft campaigns. The CLASSIC curve is simply the size distribution given by the average mixture of fresh and aged BBA species in the model. Each of these CLASSIC modes is represented by a single log-normal. Both modes have a small standard deviation of 1.3 and the mean diameters are $0.2 \mu \mathrm{m}$ for the fresh mode and $0.24 \mu \mathrm{m}$ for the aged mode. Combining these gives a fairly narrow distribution peaking in the accumulation mode. The GLOMAP-mode size distribution is the sum of all five modes (nucleation, Aitken soluble and insoluble, accumulation soluble, coarse soluble). Each campaign includes data from a common PCASP instrument, but SAMBBA included a GRIMM OPC behind a low-turbulence inlet and a Scanning Mobility Particle Sizer (SMPS). These instruments provide a dry aerosol size distribution as heating tends to remove water from the measured aerosol samples. The three instruments from SAMBBA are in good agreement regarding the shape of the accumulation mode and the rate of decline from the accumulation to coarse mode $(0.3-1 \mu \mathrm{m})$. To avoid mismatches from sampling different total concentrations, the PCASP size distributions have been normalized to give a total concentration of unity, and other observed and modelled curves have been normalized to match the peak amplitude of the PCASP.

The dry particle size distribution simulated by GLOMAPmode is shown in Fig. 8 and matches the observed size distributions remarkably well. The broad peak in aerosol number around $0.2 \mu \mathrm{m}$ and the rate of decline either side of the peak seem well supported by the available observations. The discrepancies between the GLOMAP-mode and observed size distributions across the coarse mode $(D>1 \mu \mathrm{m})$ are most likely because mineral dust is not represented in this version of the modal scheme (this is certainly the reason in the DABEX case; Fig. 8b). Another potential issue in the Amazon case is the absence in the model of any representation of primary biological aerosol particles which may contribute significantly to the observed coarse mode in this forested region (e.g. Martin et al., 2010), though such particles are only likely to be important in the surface mixed layer. Also, measurements of low concentrations of supermicron particles will have bigger uncertainties than measurements of the accumulation-mode peaks. The agreement between GLOMAP-mode and the observations across the accumulation mode $(0.1-0.6 \mu \mathrm{m})$ is partly due to a well-chosen initial size distribution that is assumed for primary emissions of BBA (this a log-normal with a mean diameter of $0.15 \mu \mathrm{m}$ and standard deviation of 1.59 as used by Stier et al., 2005). This sets the mass and number of particles emitted into the Aitken insoluble mode. Subsequently, as a result of ageing these particles grow and are transferred to the accumulation soluble mode, where most of the BC and OA mass ultimately 


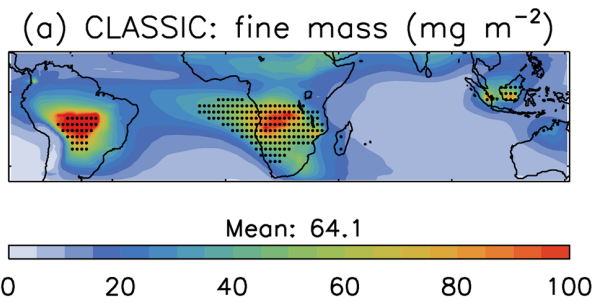

(b) GLOMAP-mode: fine mass $\left(\mathrm{mg} \mathrm{m}^{-2}\right.$ )
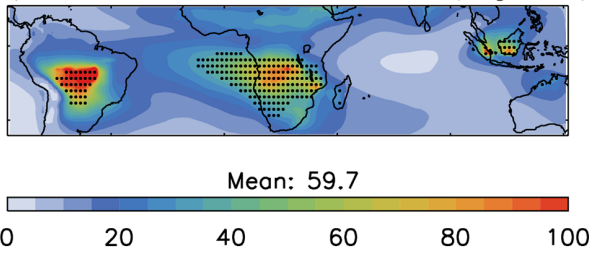

(c) CLASSIC: OA (\%)

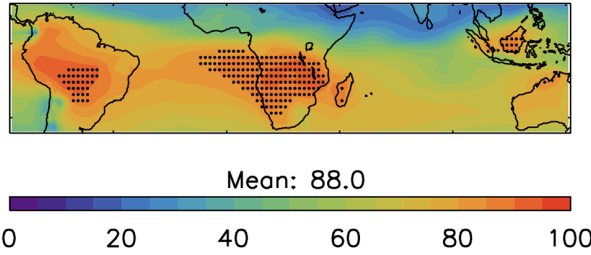

(d) GLOMAP-mode: OA (\%)

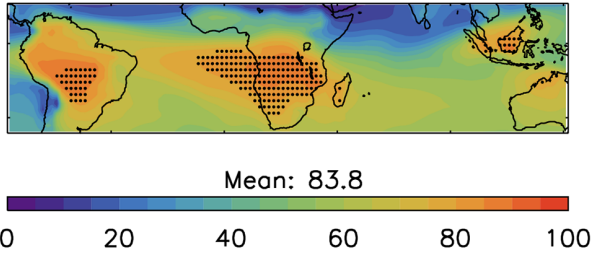

(e) CLASSIC: BC (\%)

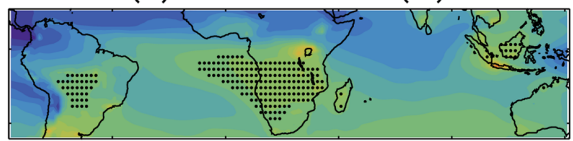

(f) GLOMAP-mode: BC (\%)

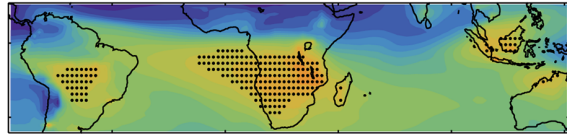

Mean: 5.1
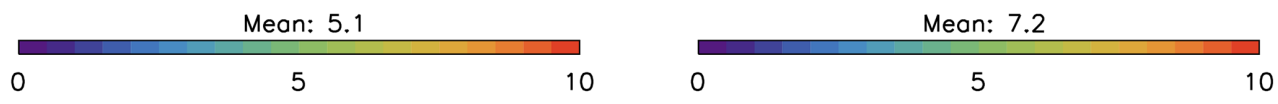

(g) CLASSIC: SU (\%)

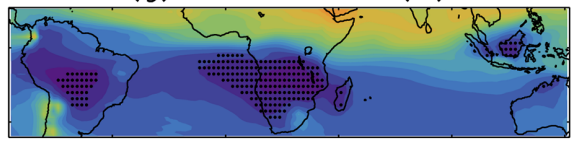

(h) GLOMAP-mode: SU (\%)
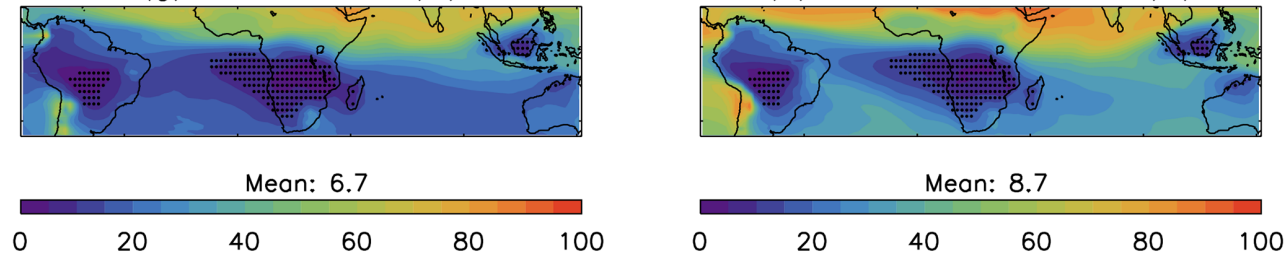

Figure 6. Modelled fine-mode aerosol composition from HadGEM3 for CLASSIC and GLOMAP-mode (including sulfate, BC, and OA only). Plots show (a, b) fine-mode mass burden $\left(\mathrm{mg} \mathrm{m}^{-2}\right),(\mathbf{c}, \mathbf{d})$ mass fraction of OA $(\%),(\mathbf{e}, \mathbf{f})$ mass fraction of BC $(\%)$, and $(\mathbf{g}, \mathbf{h})$ mass fraction of sulfate (\%). Stipples indicate grid columns where more than $75 \%$ of the fine-mode aerosol mass originates from biomass burning emissions (based on the speciation in the CLASSIC simulation). Mean values beneath each plot give the average from grid columns marked by these stipples.

resides. Here coagulation and condensation create an internal mixture of sulfate, sea salt, $\mathrm{OC}, \mathrm{BC}$, and water from all modelled sources. The combination of a well-chosen initial size distribution for the primary emissions, and subsequent microphysical and chemical processes operating through the modal framework, are therefore very successful in predicting the aerosol size distribution over BB regions.

CLASSIC provides a reasonable representation of the aerosol size distribution through the centre of the accumulation mode $(0.1-0.6 \mu \mathrm{m})$ that is most important for optical properties in the visible and near-infrared spectrum. CLASSIC naturally fits the SAFARI-2000 PCASP observations (Fig. 8c), on which it was originally based (Stier et al., 2005), but also fits the DABEX and SAMBBA observations reasonably well across the intended size range.
It is interesting to note that the observed size distributions do not vary greatly across the accumulation mode $(0.1-$ $0.6 \mu \mathrm{m}$ ) between the three BB campaigns. These campaigns span three of the main continental source regions of BBA (Fig. 9a) and include a range of biomes and fire conditions. This finding of little variation in size distribution between different biomass burning source regions suggests the approach of using a globally representative size distribution in CLASSIC, and of using a single "emission size distribution" for all primary biomass burning emissions in GLOMAPmode is a reasonable approximation. We note however that Dentener et al. (2006) present a synthesis of observations from a wider collection of observations, suggesting considerable variation in size distribution (their Figs. $\mathrm{C} 1$ and $\mathrm{C} 2$ ). These indicate apparently large changes in physical and op- 

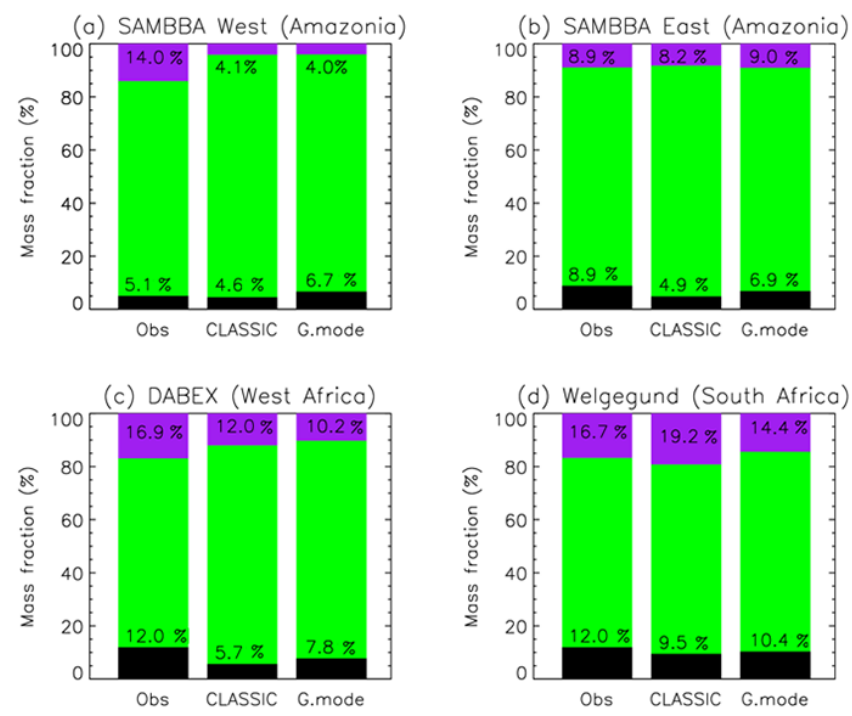

$$
\square \text { BC } \square \text { OA } \square \text { Sulphate }
$$

Figure 7. Mass fractions (\%) of black carbon (black), organic aerosol (green), and sulfate (purple) (excluding other finemode aerosol components). Observed data are monthly averages from field campaigns, including SAMBBA (Amazonia, September 2012), DABEX (West Africa, January 2006), and the Welgegund site (South Africa, September 2010). Modelled data are long-term monthly mean values corresponding to the month and location of the observations. Welgegund model data are for aerosol composition at the surface (lowest model level); SAMBBA and DABEX model data are averaged over $0-5 \mathrm{~km}$. The $\mathrm{BC}$ and sulfate mass fractions are labelled on each bar.

tical properties between different biomass burning source regions and/or following ageing of plumes. The large differences shown in Dentener et al. (2006) could in part be related to differences in systematic biases or sizing corrections applied to differences instruments, while here we present coherent results from essentially the same instrument (Fig. 9b).

\subsubsection{Comparison with AERONET size distributions}

In Fig. 10 AERONET retrievals of particle size distribution are used as an additional constraint to assess the modelled aerosol size distribution. These are given in terms of particle volume across the fine and coarse modes $(0.1-15 \mu \mathrm{m})$ and all distributions have been normalized to give peak amplitudes of 1 . The overall shape of the distribution varies very little from year to year (Fig. 10a), with a dominant fine mode peaking around $0.3 \mu \mathrm{m}$. The relative contribution from coarse-mode particles varies from year to year but is generally small. A similar analysis was performed for Mongu and produced an almost identical fine-mode size distribution giving some confidence that Alta Floresta is representative for tropical biomass burning regions.

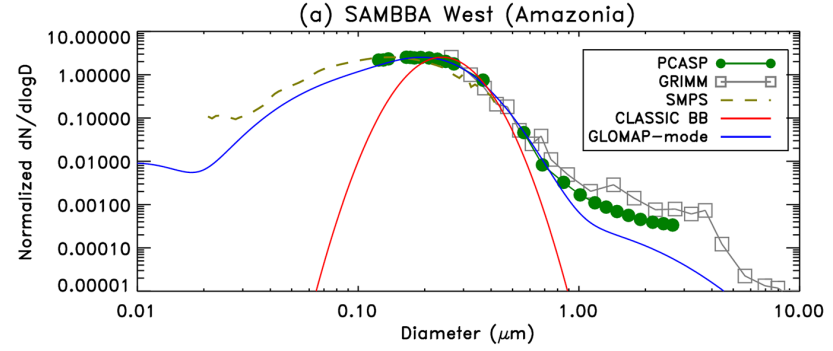

(b) DABEX (West Africa)

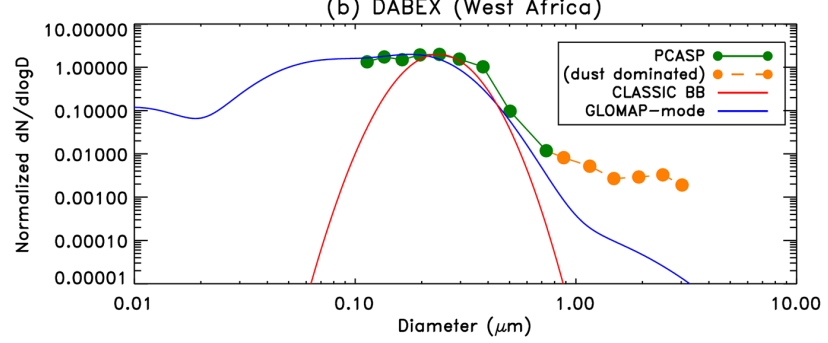

(c) SAFARI-2000 (Southern Africa)

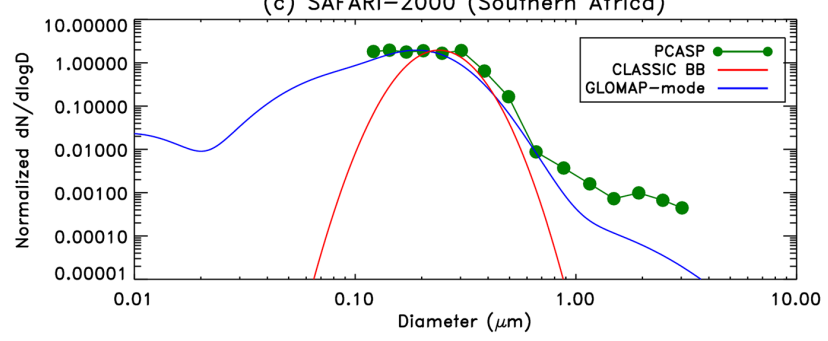

Figure 8. Aerosol number size distributions (dN/dlogD) vs. particle diameter from aircraft observations (PCASP, GRIMM, SMPS) showing the mean distribution from three campaigns. CLASSIC curve is a representative mixture of $10 \%$ fresh and $90 \%$ aged BBA species; GLOMAP-mode is the complete size distribution over all five modes averaged over the flight regions in Fig. 1 and over 0 $5 \mathrm{~km}$.

Figure 10b compares the AERONET size distribution to the PCASP and GRIMM OPC aircraft instrument data from the western SAMBBA region. Again, all size distributions have been normalized to give the same peak amplitude. It is encouraging that the PCASP gives an almost identical size distribution to AERONET across the fine mode. The GRIMM OPC size distribution covers only a portion of the fine-mode size range, but the data are consistent with the existence of a peak at $0.3 \mu \mathrm{m}$, a minimum around $1 \mu \mathrm{m}$ and a peak at coarser sizes. The aircraft instruments do not agree so well with AERONET on the amplitude or diameter of the coarse mode. The coarse-mode could be a mixture of mineral dust, primary biogenic particles, or fly ash from BB (Martin et al., 2010). Sampling issues (e.g. altitude) may be a large source of representativeness error in the PCASP and GRIMM measurements of super-micron particles. However, the coarse mode is not the focus of the assessment here, as the sources are unclear and it contributes very little (5-10\%) to the AOD or optical properties. 
(a) Three regions compared: GLOMAP-mode

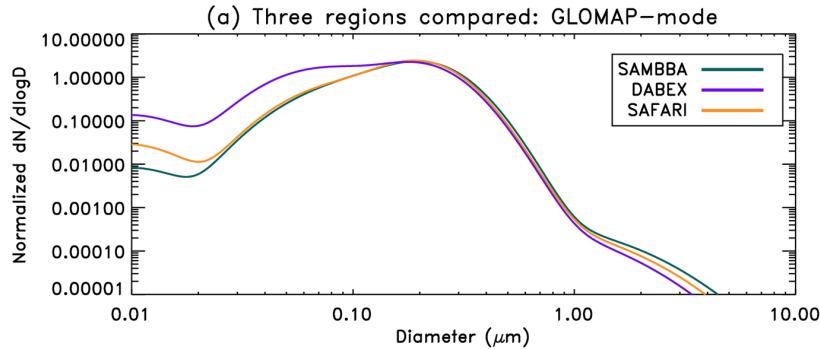

(b) Three regions compared: PCASP

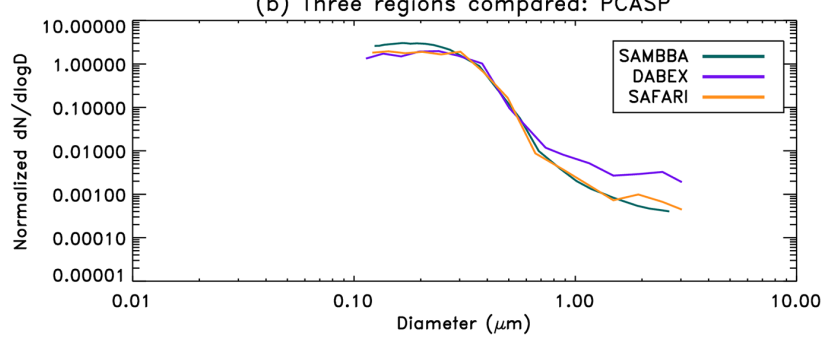

Figure 9. Same as Fig. 7 but showing only GLOMAP-mode curves and PCACP data.

Figure 10c compares the mean AERONET size distribution with the models. For CLASSIC the size distribution of the BBA species is plotted, whereas GLOMAPmode is the column mean for September co-located with Alta Floresta. Both modelled size distributions peak at about the same diameter $(\sim 0.3 \mu \mathrm{m})$ as AERONET. The CLASSIC size distribution is a little narrower than AERONET, whereas GLOMAP-mode predicts about the same width as AERONET. This increases confidence that GLOMAP-mode is able to predict aerosol size distributions accurately, and is an improvement over the specified distribution in CLASSIC.

\subsection{Optical properties}

In this section the aerosol optical properties from the models are compared and evaluated against AERONET retrievals and in situ measurements from aircraft campaigns. The methods for deriving optical properties are described below and results are then discussed separately for each optical property.

Firstly the column-average moist aerosol properties have been calculated from the models to assess how these vary regionally in the two aerosol schemes. The fine-mode specific extinction coefficient $\left(k_{\text {ext,fm }}\right)$ (Fig. 11a and b) was calculated as the ratio of fine-mode moist AOD to fine-mode dry aerosol mass. In GLOMAP-mode the fine mode includes the Aitken soluble, Aitken insoluble, and accumulation-soluble modes. In CLASSIC the fine mode is taken to include all sulfate and carbonaceous aerosol species. The single scattering albedo (SSA) (Fig. 11c and d) has been calculated from the AOD and absorption AOD (AAOD) at $550 \mathrm{~nm}$, and the Ångström exponent ( $\AA$ ) (Fig. 11e and f) is calculated from the wavelength dependence of AOD across 440-670 nm. The stipples (a) AERONET Alta Floresta 2002-2011, Sep means

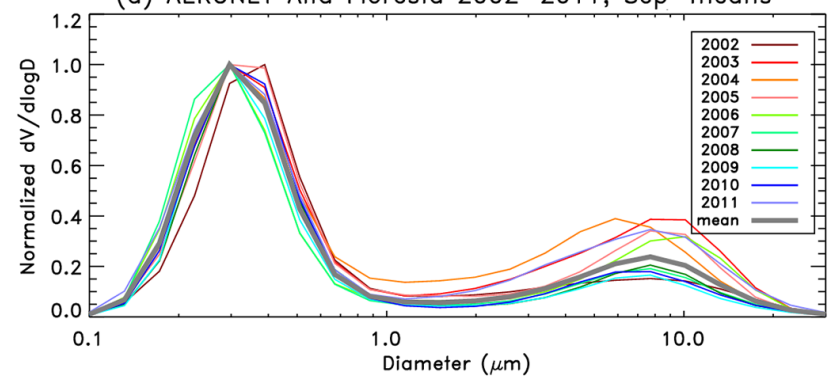

(b) AERONET vs. SAMBBA FAAM obs

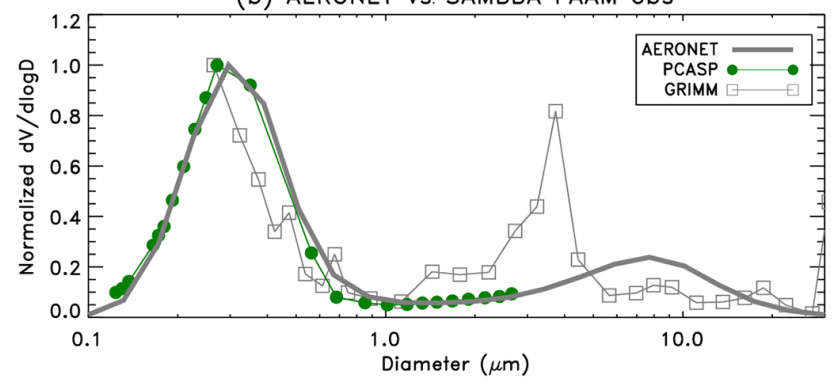

(c) AERONET vs. models

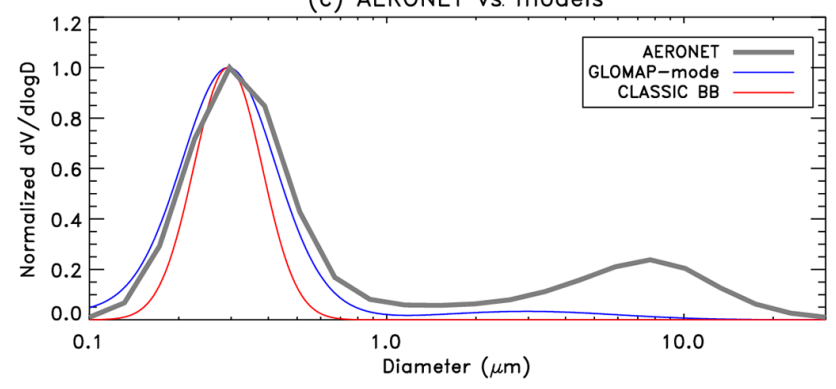

Figure 10. Aerosol volume size distributions $\left(\mathrm{d} V / \mathrm{d} \log D \mu \mathrm{m}^{3} \mu \mathrm{m}^{-2}\right)$ vs. particle diameter for (a) September means from AERONET Alta Floresta (southern Amazonia) for 2002-2011 along with the long-term monthly mean from all years, (b) comparison of the AERONET 10-year September mean with FAAM averages from the SAMBBA West region, normalized by peak concentration, and (c) comparison of the AERONET 10-year September mean with HadGEM3 September monthly mean output, the column-integrated mean over Alta Floresta for GLOMAP-mode (all active size modes), and CLASSIC (BB species only).

in Fig. 11 mark grid columns where over $75 \%$ of the finemode aerosol mass originates from BBA emissions (as in Fig. 6, based on CLASSIC speciation) and the mean values beneath each plot indicate the mean from the stippled areas.

Secondly, the modelled SSA and $\AA$ are compared for all months against AERONET retrievals for Alta Floresta and Mongu (Fig. 12). Monthly mean SSA retrievals were not available in all months of the year due to low temporal sampling frequency outside of the dry season (inversions require AOD $>0.4$ and cloud-free skies). In addition to AERONET level 2 criteria we only accept a monthly mean if data were available from at least 3 separate days in that month, and only calculate the long-term monthly mean if at 

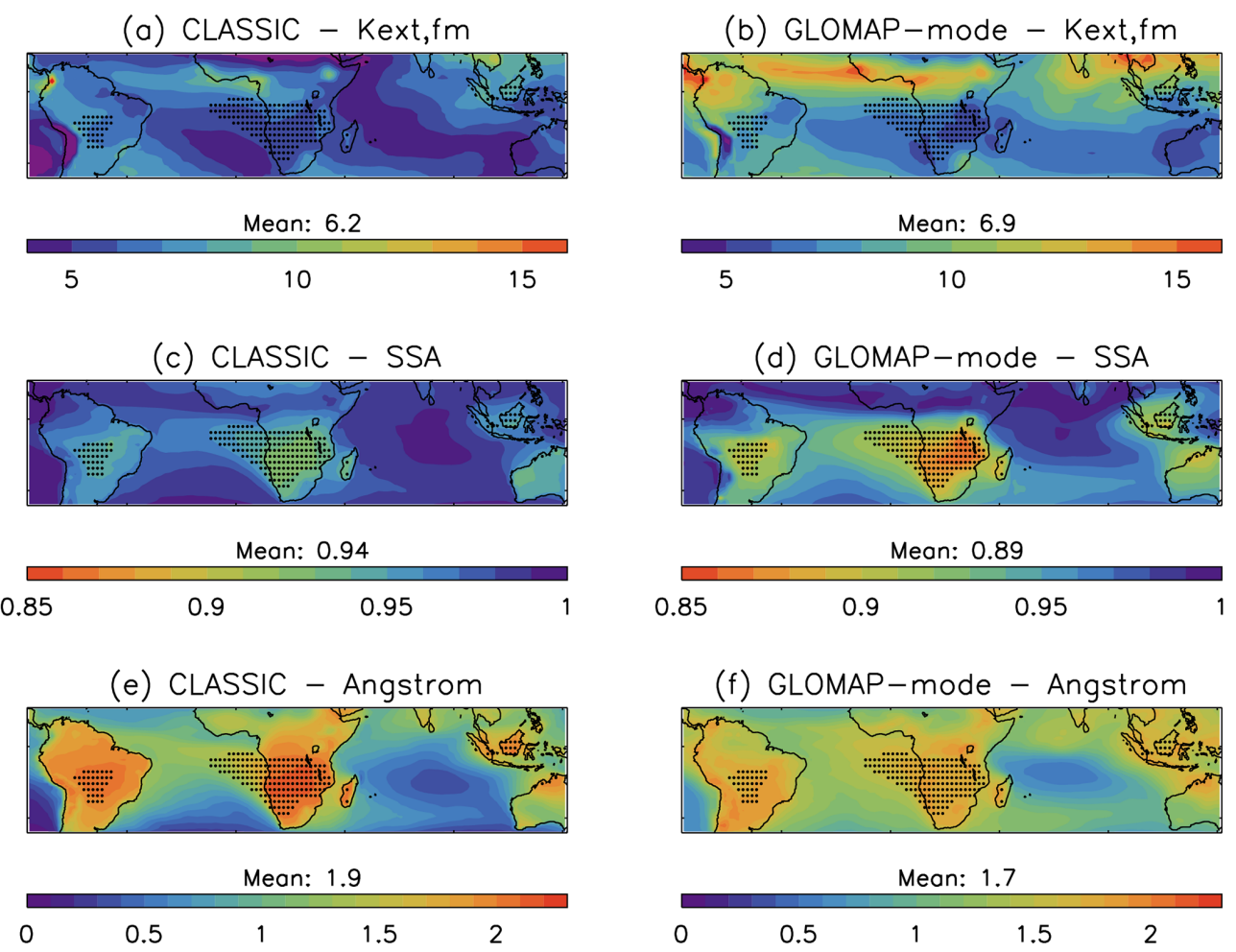

(f) GLOMAP-mode - Angstrom

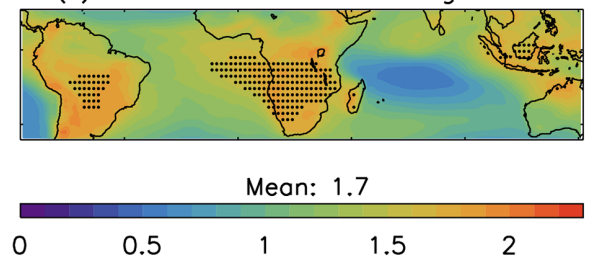

Figure 11. Column average moist aerosol optical properties from CLASSIC and GLOMAP-mode for the September long-term monthly mean. Properties are the fine-mode specific extinction coefficient $\left(k_{\text {ext,fm}}\right)$, single scattering albedo (SSA) and the Ångström exponent. Stipples indicate grid columns where more than $75 \%$ of the fine-mode aerosol mass originates from biomass burning emissions (based on the speciation in the CLASSIC simulation). Mean values beneath each plot give the average from grid columns marked by these stipples.

least three monthly means were available in the time series. The AERONET retrievals of Å relied on direct Sun measurements of AOD at 440 and $670 \mathrm{~nm}$ and have better temporal sampling, enabling long-term monthly means to be calculated for every month.

Finally, Table 2 compares dry aerosol optical properties of $\mathrm{SSA}, \AA$, $k_{\text {ext,ffm }}$, and asymmetry parameter $(g)$ from the models and from the mean values from the aircraft campaigns (references provided in the table). The comparison is made for dry aerosol since heating tends to dry the aerosol samples measured by the aircraft instruments. For CLASSIC, the optical properties are specified, and so values in Table 2 are simply derived by averaging together the optical properties for fresh and aged BBA species, based on the typical mixture simulated over the BB regions (10\% fresh, $90 \%$ aged). For GLOMAP-mode the dry optical properties in Table 2 were calculated from Mie theory using the dry size distribution and refractive index for each of the fine modes (Aitken soluble, Aitken insoluble, and accumulation-soluble) and then averaged across the mode weighting by total extinction (or by scattering for $g$ ).

\subsubsection{Fine-mode specific extinction coefficient $\left(k_{\text {ext,fm }}\right)$}

The fine-mode moist specific extinction (Fig. 11a and b) varied quite widely in both models, but was generally higher in GLOMAP-mode, especially in areas where sulfates were more dominant (see Fig. 6h). This is due to a high water uptake by sulfate in the current GLOMAP-mode configuration. In the main BB plumes (marked by stipples), where OA dominates the aerosol mass, the values of $k_{\text {ext.fm }}$ range from 5 to $10 \mathrm{~m}^{2} \mathrm{~g}^{-1}$, with the highest values in both models over the moister regions of Indonesia and the lowest values in southern Africa where the average relative humidity was lower in the lower troposphere (not shown). The average values from the BB plumes (stippled areas) are fairly similar, with a slightly lower value of $6.2 \mathrm{~m}^{2} \mathrm{~g}^{-1}$ for CLASSIC and a value of $6.9 \mathrm{~m}^{2} \mathrm{~g}^{-1}$ for GLOMAP-mode. Note that these values are indicative rather of the aerosol mixture as a whole, and so are also affected by the representation of other aerosols. In Table 2 the dry values of $k_{\text {ext,fm }}$ are similar for CLASSIC $\left(5.0 \mathrm{~m}^{2} \mathrm{~g}^{-1}\right)$ and GLOMAP-mode $\left(4.5-4.8 \mathrm{~m}^{2} \mathrm{~g}^{-1}\right)$ and are within the range given by the aircraft measurement campaigns $\left(3.6-5.8 \mathrm{~m}^{2} \mathrm{~g}^{-1}\right)$. Note that in this case the dry value given for CLASSIC corresponds to the BB species only. 
Table 2. Dry aerosol optical properties at $550 \mathrm{~nm}$ from model and observations including single scattering albedo (SSA), the Ångström exponent $(\AA)$, the fine-mode specific extinction coefficient $\left(k_{\text {ext,fm }}\right)$, and asymmetry parameter $(g)$. Error bounds are given to observed parameters, where available, to reflect uncertainty in the measurement.

\begin{tabular}{|c|c|c|c|c|c|c|}
\hline Data source & Campaign/region & $\begin{array}{r}\text { SSA } \\
\left(\mathrm{m}^{2} \mathrm{~g}^{-1}\right)\end{array}$ & $\AA$ & $k_{\text {ext,fm }}$ & $g$ & References \\
\hline \multicolumn{7}{|l|}{ Models } \\
\hline 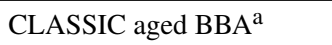 & Global & 0.91 & 2.3 & 5.0 & 0.58 & Haywood et al. (2003) \\
\hline \multirow[t]{4}{*}{ GLOMAP-mode fine-mode } & SAMBBA West (Rondonia) & 0.87 & 2.0 & 4.8 & 0.63 & \\
\hline & SAMBBA East (Tocantins) & 0.86 & 2.1 & 4.5 & 0.60 & \\
\hline & DABEX (West Africa) & 0.85 & 2.0 & 4.6 & 0.61 & \\
\hline & SAFARI (Southern Africa) & 0.86 & 2.0 & 4.8 & 0.62 & \\
\hline \multicolumn{7}{|l|}{ Observations } \\
\hline \multirow[t]{4}{*}{ In situ aircraft observations } & $\begin{array}{l}\text { SAMBBA West } \\
\text { (Phase 1, Rondonia) }{ }^{\mathrm{b}}\end{array}$ & $0.88 \pm 0.05$ & $1.9 \pm 0.3$ & $3.6 \pm 0.06$ & $\begin{array}{l}{ }^{\mathrm{c}_{0}} 0.66 \pm 0.06 \\
\mathrm{~d}_{0.59} \pm 0.05\end{array}$ & $\begin{array}{l}\text { Darbyshire et al. (2016); } \\
\text { Brooke (2014) }\end{array}$ \\
\hline & SAMBBA East (Tocantins) & 0.79 & $2.1 \pm 0.2$ & NA & $0.57 \pm 0.05$ & Darbyshire et al. (2016). \\
\hline & DABEX (West Africa) & $0.81 \pm 0.05$ & 1.7 & 5.8 & 0.63 & Johnson et al. (2008b) \\
\hline & SAFARI-2000 (Southern Africa) & $0.88 \pm 0.04$ & NA & 4.3 & 0.58 & Haywood et al. $(2003)^{\mathrm{e}}$ \\
\hline
\end{tabular}

${ }^{\mathrm{a}}$ Assuming a representative mixture with $10 \%$ fresh and $90 \%$ aged BB aerosol. ${ }^{\mathrm{b}}$ Phase 1 of SAMBBA was from 14 to 22 September $2012 .^{\mathrm{c}}$ Calculated from the nephelometer backscatter fraction based on Andrews et al. (2006). ${ }^{\mathrm{d}}$ Derived from Mie calculations in Brooke (2014). ${ }^{\mathrm{e}}$ Haywood et al. (2003) results for SSA reassessed in Johnson et al. (2008b).
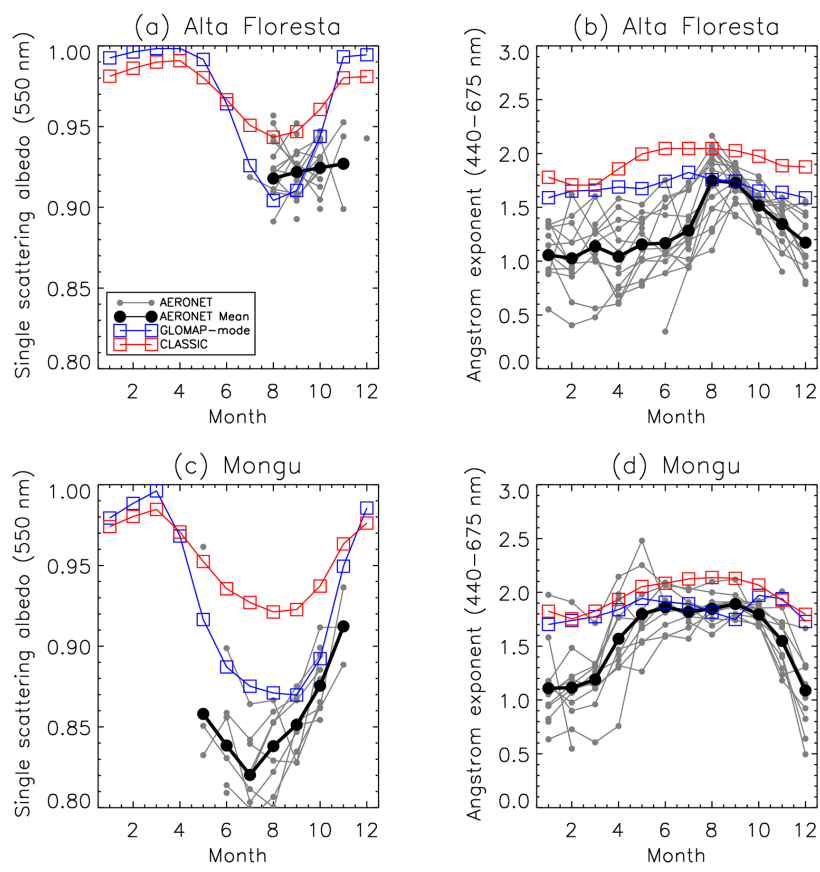

Figure 12. Seasonal cycle of moist aerosol optical properties (single scattering albedo and Ångström exponent). AERONET data from Alta Floresta (southern Amazonia) and Mongu (southern Africa) include all available monthly means (grey) and the long-term monthly mean (black) for months with good data coverage (see text). Colocated model data from GLOMAP-mode (red) and CLASSIC (blue) are shown taking the column average long-term monthly means.

\subsubsection{Single scattering albedo (SSA)}

The SSA of aerosol over BB dominated regions was generally lower in GLOMAP-mode than in CLASSIC for both the ambient (moist) values (Figs. 11c and d, 12a and c) and dry values (Table 2). This is consistent with the higher BC mass fraction in GLOMAP-mode (Fig. 7). The lower dry SSA values from GLOMAP-mode (0.85-0.87) agree better with the range from the aircraft campaigns $(0.79-0.88)$ than CLASSIC (0.91). The ambient SSA values from GLOMAP-mode during the dry season (July-October) (0.87-0.94) also agree better with AERONET observations from Alta Floresta and Mongu (Fig. 12a and c). The ambient SSA also shows a high degree of spatial variability in both models (Fig. 11c and d). These variations are mainly caused by variability of composition and water content. As shown in Sect. 3.5 the hygroscopic growth may be overestimated in both models so the spatial variation of ambient SSA and its relation to humidity may not be entirely realistic. However, the AERONET observations do show a contrast between the drier region of southern Africa (represented by the Mongu site in Fig. 11c), where the long-term monthly mean SSA drops to 0.82-0.85 during July-September, and the moister Amazonian region (represented by the Alta Floresta site in Fig. 11a), where the long-term monthly SSA is around 0.92 during AugustSeptember. This observed variation may be explained more by variations in $\mathrm{BC}$ content rather than due to variations in hygroscopic growth. There is likely a higher BC content in the aerosol column over Mongu due to the drier vegetation burning more through flaming combustion (some evidence for the higher BC content is found in Fig. 7d for the Welgegund observations that are in the same continental region). 


\subsection{3 Ångström exponent $(\AA)$}

The CLASSIC aerosol scheme gives a fairly high Ångström exponent with a dry value of 2.3 for the BBA species (Table 2), and moist values of 1.9-2.1 for the fine-mode aerosol mixture over BB dominated regions (Fig. 11e). This is due to the fairly narrow size distribution assumed in CLASSIC. These values of $\AA$ are somewhat outside the observed range from the aircraft campaigns (dry values of 1.7-2.1 from nephelometer measurements) and AERONET (longterm monthly mean moist values of 1.7-1.9). GLOMAPmode gives slightly lower values of $\AA$ than CLASSIC, with dry values ranging from 2.0 to 2.1 (Table 2), and ambient (moist) values ranging from 1.5 to 1.9 over the $\mathrm{BB}$ regions (Fig. 11f). These agree quite well with the aircraft observations and AERONET observations during the peak of the burning season (August-September) (Fig. 12b and d). The seasonal variation of $\AA$ observed by AERONET (i.e. the drop to lower values outside the burning season in Fig. 12b and d) is not well captured in either model. This could be due to insufficient representation of coarse particles, such as mineral dust or primary organic particles outside the BB season.

\subsection{Hygroscopic growth}

The hygroscopic growth of aerosol (i.e. the growth of the aerosol with relative humidity due to the uptake of water) leads to enhanced scattering. This can be expressed via the scattering growth factor $\left(\mathrm{GF}_{\mathrm{sca}}\right)$, which is the observed or modelled scattering of the aerosol at ambient humidity divided by the scattering of the same aerosol when completely dried (i.e. at very low relative humidity). For CLASSIC the hygroscopic growth is specified via an empirical fit that reproduces the $\mathrm{GF}_{\text {sca }}$ curve observed by Magi and Hobbs (2003), hereafter MH03. In MH03 GF $_{\text {sca }}$ curves were derived from a humidified nephelometer system operated on flights over southern Africa during SAFARI-2000. MH03 parameterized the $\mathrm{GF}_{\text {sca }}$ curves for a range of aerosol conditions and the CLASSIC scheme uses their "heavy smoke" curve for the fresh BBA species, and their "regional air" curve for the aged BBA species. These $\mathrm{GF}_{\text {sca }}$ curves are shown on Fig. 13, along with a representative curve for CLASSIC assuming a mixture with $10 \%$ fresh BBA and $90 \%$ aged BBA. These give a very strong increase in scattering with $\mathrm{RH}$ for the CLASSIC BBA, with $\mathrm{GF}_{\text {sca }}$ rising to 2.05 at $80 \%$ and to 3.4 at $100 \%$. With similar instrumentation Kotchenruther and Hobbs (1998), hereafter KH98, found much lower $\mathrm{GF}_{\text {sca }}$ for $\mathrm{BB}$ dominated aerosol over Brazil (Fig. 13). For RH $>65 \%$ the range from KH98 does not overlap that from $\mathrm{MH} 03$, and at $80 \%$ the range from $\mathrm{KH} 98$ is only 1.05-1.29. The large difference between these two observation sets is difficult to reconcile, especially as both were derived from an airborne humidified nephelometer system. Possibly the regional aerosol mixture (categorized as "regional air" in MH03) contained a substantial proportion of

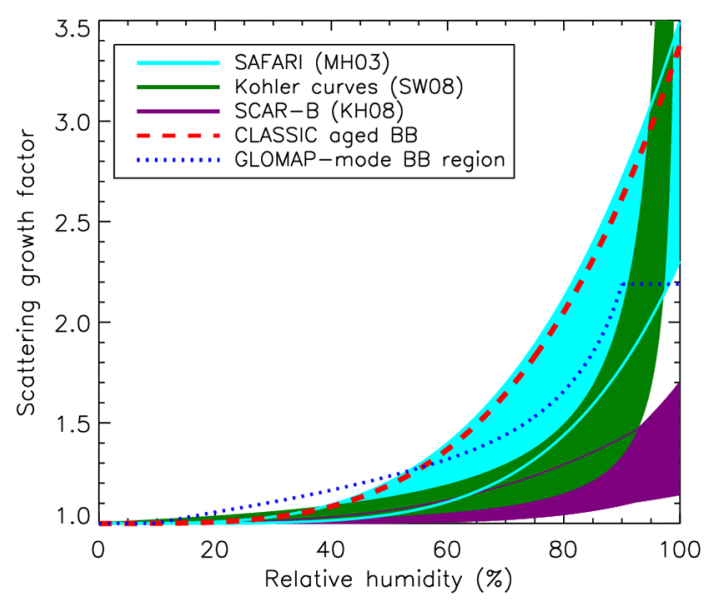

Figure 13. Hygroscopic growth curves showing the increase in aerosol scattering at $550 \mathrm{~nm}$ with ambient relative humidity from a variety of observational sources and from the models. The curve for CLASSIC assumes a mixture of $10 \%$ fresh and $90 \%$ aged BBA. The curve for GLOMAP-mode is calculated based on the average composition from the four BB regions in Fig. 7. The solid filled areas show the range of growth factors estimated from each observation source (see text).

highly hygroscopic sulfate from industrial sources in southern Africa and is therefore not representative of purely carbonaceous aerosol.

Additional constraints on hygroscopic growth have been provided more recently from Hygroscopic Tandem Differential Mobility Analyzer (H-TDMA) instruments. A wide range of measurements, including Amazonian aerosol are summarized in the review of Swietlicki et al. (2008). More recent measurements for Amazonia are also provided in Whitehead et al. (2014). In these analyses the hygroscopic growth is summarized via the "kappa" parameter $(\kappa)$ that can be used to reconstruct the growth curve from Kohler theory. Swietlicki et al. (2008) give a range of $\kappa$ values of $0.05-0.15$ for Amazonian dry season/BB conditions, leading to $\mathrm{GF}_{\text {sca }}$ of $1.16-1.49$ at $80 \%$. The Kohler curves based on this range of $\kappa$ are also plotted in Fig. 13. For RH $<90 \%$ the Kohler curves provide an intermediate range of growth factors that overlap the upper range from KH98 and the lower range from MH03. However, the Kohler curves have greater curvature and rise very steeply for $\mathrm{RH}>80 \%$ and exceed the range from MH03 for $\mathrm{RH}>95 \%$. This reflects the increasing level of uncertainty in $\mathrm{GF}_{\text {sca }}$ at higher $\mathrm{RH}$ where growth factors become increasingly difficult to verify from the observations. Both the empirical fits in KH98 and MH03, and the theoretical Kohler curves are essentially extrapolated from the observed growth up to 80 or $90 \%$.

For GLOMAP-mode the hygroscopic growth curve is calculated based on the Zdanovski-Stokes-Robinson (ZSR; Stokes and Robinson, 1966) mixing rule. For this comparison we take the average fine-mode composition from the four 
regions/sites in Fig. 7, which gives a mixture with $82.6 \%$ organic carbon, $9.4 \%$ sulfate, and $8 \%$ black carbon. The black carbon is assumed to be hydrophobic, whereas organic carbon is assumed hydrophobic when in the Aitken insoluble mode (where approximately one-third of the OA resides) and hygroscopic in the soluble modes (most of the remaining two-thirds of OA). The water uptake by soluble OA is based on sulfuric acid but scaled down such that the carbonaceous aerosol from BB takes up approximately $25 \%$ of the water of an equivalent dry mass of $\mathrm{H}_{2} \mathrm{SO}_{4}$. The $\mathrm{GF}_{\text {sca }}$ curve in GLOMAP-mode is capped at a RH of $90 \%$ to avoid overestimation of aerosol scattering and AODs close to saturation. For relative humidity above $60 \%$ GLOMAP-mode gives lower $\mathrm{GF}_{\text {sca }}$ than CLASSIC, with $\mathrm{GF}_{\text {sca }}$ reaching 1.66 at $80 \%$ and 2.19 for $90-100 \%$ (compared to 2.1 and 2.63.4 for CLASSIC). For RH $<60 \%$ GLOMAP-mode has a slightly higher $\mathrm{GF}_{\mathrm{sca}}$ than CLASSIC and has an unrealistic shape, but this is unlikely to be important compared to the difference at higher $\mathrm{RH}$.

Overall, although there is large uncertainty from the observations, it seems likely that the CLASSIC scheme overestimates the $\mathrm{GF}_{\mathrm{sca}}$ and therefore aerosol scattering, $\mathrm{AOD}$, and single scattering albedo for BBA in moist conditions (e.g. RH $>60 \%$ ). GLOMAP-mode may also overestimate the hygroscopic growth, though to a lesser extent. The representation of hygroscopic growth could be improved in both aerosol schemes. One option would be to use Kohler curves with observationally constrained $\kappa$ values, though care would be needed in dealing with the growth assumed at the upper $\mathrm{RH}$ range.

\subsection{Vertical distribution of aerosol}

The vertical distribution of BBA in the models depends on the vertical profile of emissions and on transport and removal processes. The emission profiles and transport processes are treated identically for the two aerosol schemes, but the representations of wet and dry removal processes are different. The modelled profiles of fine-mode aerosol mass are assessed in Fig. 14 by comparing them with campaign mean aircraft observations. For the SAMBBA and DABEX cases the observed profile of fine-mode mass has been estimated from the nephelometer measurement of dry aerosol scattering multiplied by the fine-mode specific extinction $\left(k_{\mathrm{ext}, \mathrm{fm}}\right)$ and SSA. Due to use of a modified Rosemount inlet serving the nephelometer on the FAAM aircraft, coarse-mode particles are not well sampled. We therefore make the assumption that the total nephelometer scattering serves as a reasonable guide to fine-mode aerosol concentration. For the conversion of scattering to fine-mode mass we take the $k_{\text {ext,fm }}$ and SSA values derived from the in situ aircraft observations in Table 2. For SAMBBA (Fig. 14a) the campaign mean profile is representative of the western Amazonia region around Porto Velho, Rondonia. The aerosol extinction coefficient derived from the airborne lidar in SAMBBA was also averaged over a range of flights observing regional BBA layers in the Amazonian region (Marenco et al., 2016). The lidar-derived extinction at $355 \mathrm{~nm}$ was converted to dry extinction at $550 \mathrm{~nm}$ using an Ångström exponent of 1.7 based on the AERONET September monthly mean at Alta Floresta (Fig. 12a) and the average humidity growth factor from KH98 (Fig. 13). For DABEX the campaign mean profile is taken from Johnson et al. (2008b) and included a correction to subtract the scattering associated with mineral dust aerosol. For SAFARI-2000 no campaign mean profile was available, but Haywood et al. (2003) provide information on the observed range of heights for the elevated layers observed over the south-eastern Atlantic. To indicate the degree of sampling error in the mean profiles, the standard error is also shown in Fig. 14 for both the observations and models. For the observations the standard error has been calculated as the standard deviation of aerosol mass at a given altitude divided by the square root of the number of profiles (for the nephelometer) or flight sections (for the lidar). For the models the standard error is calculated as the standard deviation from the 10 monthly mean profiles in each simulation divided by the square root of 10 (the number of years).

The two models predict very similar vertical distributions of fine-mode aerosol with approximately the same profile shape and magnitude of aerosol mass. In most places differences between the models are comparable to the standard error associated with interannual variability. The models also agree quite well with the observations in terms of reproducing the basic vertical structure and profile shape. Over Amazonia the observed profile shows a fairly well-mixed layer up to $1.5 \mathrm{~km}$, a small increase around $1.5-2 \mathrm{~km}$, and then a gradual decline from 2 to $6 \mathrm{~km}$ and very little above $6 \mathrm{~km}$. The lidar gives a similar shaped profile to the nephelometer except with a more pronounced peak around $2 \mathrm{~km}$. Although the concentrations of aerosol mass observed during SAMBBA were highly variable in space and time (Marenco et al., 2016), the relatively low standard error shows that by averaging over a sufficient sample of flight sections (lidar) or profiles (nephelometer) the campaign mean nephelometer and lidar profiles do provide a useful guide for evaluating the models. The lidar and nephelometer profiles are not expected to match exactly as the spatial and temporal sampling frequency was different and lidar profiles are more uncertain near the ground. Both models capture the shape of the observed profiles reasonably well, even showing the increase around $2 \mathrm{~km}$. During DABEX the BB dominated aerosol layers were observed to reside in an elevated layer from 1.5 to $5 \mathrm{~km}$ with only low concentrations below. These elevated layers originated from BB emissions further south but had been undercut by Saharan air, lofted and transported north and west towards the observed region (mainly around Niamey, Niger). The models capture the elevated layer but predicted concentrations are lower than observed. During SAFARI-2000 the BB dominated aerosol over the southeastern Atlantic was observed to reside in elevated layers 
(a) SAMBBA West

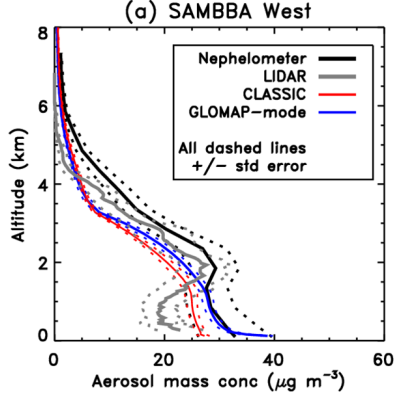

(b) DABEX

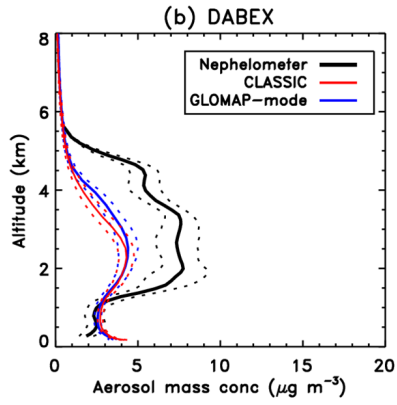

(c) SAFARI-2000 SE Atlatic

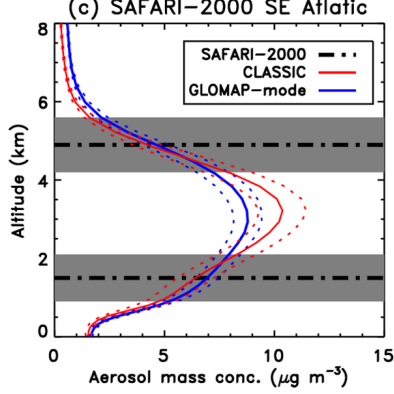

Figure 14. Vertical profiles of fine-mode aerosol mass concentration for the SAMBBA, DABEX, and SAFARI-2000 airborne campaigns, including model averages for CLASSIC (red) and GLOMAP-mode (blue). Dashed lines show the mean \pm the standard error. Profiles of mass concentrations have been estimated from campaign-averaged nephelometer (black) and lidar (green) observations using the fine-mode specific scattering $\left(k_{\text {sca,fm }}\right)$ and extinction coefficients $\left(k_{\text {ext,fm }}\right)$, respectively, derived from the in situ aircraft observations (see the second half of Table $2 ; k_{\text {sca,fm }}=$ $k_{\text {ext,fm }} \times$ SSA). The SAFARI-2000 observations indicate the average altitude of the BBA layer base and top (black dot-dashed line) \pm the standard deviation (grey shading).

with a fairly consistent layer base at $1.5 \pm 0.6 \mathrm{~km}$ and a layer top at $4.9 \pm 0.7 \mathrm{~km}$. The models both simulate an elevated layer peaking within this altitude range but with some spread above and below the observed limits of the layers. The two models give very similar vertical profiles though the mass concentration peaks at slightly higher values in CLASSIC in the centre of the layer.

Overall the results show that HadGEM3 predicts the vertical profile of BBA quite well despite the current rather crude set of assumptions for plume injection height. As detailed in Sect. 2.3 the emissions from savannah were injected at the surface and emissions from forest/deforestation uniformly over the lowest $3 \mathrm{~km}$. More sophisticated approaches where plume injection heights are predicted online in the model should certainly be investigated, but it is encouraging that the current approach works reasonably well for the cases investigated here.

\section{Conclusions}

We conclude that the implementation of GLOMAP-mode has improved the representation of biomass burning aerosol in HadGEM3. The modal scheme is able to predict the full aerosol size distribution and simulate the variation of aerosol composition and optical properties giving the scheme increased accuracy over the CLASSIC bulk scheme of HadGEM2-ES. The simulated aerosol properties, AOD, and aerosol vertical distribution are shown to compare well with observations from SAMBBA and two other aircraft campaigns (DABEX, SAFARI-2000), and with remote sensing retrievals from MODIS and AERONET.

The analysis of field observations showed biomass burning aerosols to have reasonably consistent size distributions, Ångström exponents (1.7-2.1), and dry specific extinction coefficients $\left(3.6-5.8 \mathrm{~m}^{2} \mathrm{~g}^{-1}\right)$ across different tropical biomass burning regions. CLASSIC represents this reasonably well by specifying a globally representative size distribution that includes the particle size range most important for interaction with solar radiation. GLOMAP-mode simulated the full size distribution from nucleation to coarse $(0.01-10 \mu \mathrm{m})$, showing realistic features with good agreement against the available observations. The agreement between modelled and observed size distributions stems from a well-constrained initial size distribution for the emitted particles, followed by a good representation of how this size distribution evolves with chemical and microphysical processes. GLOMAP-mode was also able to predict the optical properties with improved accuracy.

However, the analyses suggest that both aerosol schemes overestimate the uptake of water at high relative humidity. This overestimation is greater in CLASSIC and is likely to cause an overestimation of aerosol scattering, AOD, and SSA in moist regions. In CLASSIC the aerosol scattering coefficient rises by a factor of 2.1 from dry conditions to $80 \%$ relative humidity, whereas in GLOMAP-mode it rises by a factor of 1.7. Although there is considerable uncertainty and variability amongst observations, recent measurements from H-TDMA suggest lower growth factors for aged BB aerosol with the factor of increase in aerosol scattering in the region of $1.2-1.5$ from dry to $80 \%$ relative humidity.

The analysis of observations in this study also highlights the strong variations in black carbon (BC) mass fraction (5$12 \%)$ and single scattering albedo (SSA) (0.79-0.88) in the average biomass burning aerosol composition from different tropical source regions. These variations are a challenge for 
the models to capture. Whilst the dry BC mass fraction and SSA in GLOMAP-mode $(7-10 \%$; $0.85-0.87)$ are closer to the observed values than CLASSIC (5-9\%; 0.91), the modelled variability between source regions is lower than observed. This may point to the need for a wider range of $\mathrm{BC}: \mathrm{OC}$ ratios in the emissions data, which in GFED3 are based on Andreae and Merlet (2001). These have been updated in GFED4 (Giglio et al., 2013) based on Akagi et al. (2011) and future studies may provide useful feedback on whether these improve the variability of aerosol composition in models. The emissions of BBA had the same prescribed vertical profile in both models and led to very similar vertical distributions of fine-mode aerosol mass over the main tropical BB regions that compared well with the airborne in situ and lidar observations.

Whilst both schemes gave good agreement between observed and modelled AODs over BB regions, this was achieved by scaling up the total aerosol emissions from GFED3.1 by a global scaling factor of 1.6 for CLASSIC and 2.0 for GLOMAP-mode. This might suggest that the emissions of BC and OC from GFED3 lead to an underestimate of the aerosol mass. However, we note that there is considerable uncertainty in other parameters in the models that affect the aerosol mass and AOD from BB sources. Firstly, there is considerable uncertainty in the ratio used to convert the OC (i.e. carbon mass provided by the emissions data) to the total mass of POM emitted in the models. This depends on the ratio of carbon to oxygen and other elements in the emitted aerosol. In the current configuration of HadGEM3 CLASSIC does not account for this issue (effectively neglecting the non-carbon mass) and GLOMAP-mode converts the OC to POM using a ratio of 1.4 that is likely too low for biomass burning emissions. On the other hand CLASSIC increases the total aerosol mass by a factor of 1.62 on a $6 \mathrm{~h}$ e-folding timescale to represent condensation growth during ageing (a process that GLOMAP-mode does not include). Therefore, the emission scaling factors required to generate agreement between modelled and observed AODs clearly depend on these other scaling applied within the aerosol schemes, as well as aerosol optical properties. For instance, the global emission scaling factor for GLOMAP-mode could be decreased from 2.0 to 1.5 if the POM: OC ratio was increased from 1.4 to 1.9 , which would still be within the range reported from observations of aerosol mixtures heavily impacted by biomass burning or wood smoke (e.g. Turpin and Lim, 2001; Aiken et al., 2008; Ng et al., 2010; Tiitta et al., 2014; Brito et al., 2014). This would reduce the black carbon emissions from BB by $25 \%$ leading to a slightly less favourable comparison of modelled chemical composition and single scattering albedo with the observations presented in this study. An upward revision to the refractive index of $\mathrm{BC}$ and/or the inclusion of browncarbon absorption could be implemented to address the reduction of $\mathrm{BC}$ absorption. Aerosol lifetimes also clearly will affect the loading of aerosol mass and AOD, implying that the global emission scaling factors could change with the representation of aerosol removal processes and the simulation of moist processes. Other models may not require emission scaling to gain good agreement with observed AODs or may require different scaling factors outside the range 1.6-2.0 found in this study. Moreover, due to the difficulties in comparing large-scale models with limited observations, these scaling factors are not precise, but rather indicate the approximate scale of the AOD biases. It is also worth noting that there are large differences between emission factors estimated for different measures of the aerosol mass: $\mathrm{BC}+\mathrm{OC}$, total carbon (TC), total particulate matter (TPM), $\mathrm{PM}_{2.5}$, and $\mathrm{PM}_{10}$ (see Andreae and Merlet, 2001; Akagi et al., 2011). For instance the emission factors for TPM are a factor of 2.3-2.4 higher than the sum of BC + OC in GFED3 (based on Andreae and Merlet, 2001) for tropical BB sectors. Using TPM instead of BC and OC in our simulations would therefore have led to an overestimation of AOD in tropical regions unless the global emission scaling factor was reduced to approximately 0.67 in CLASSIC and approximately 1.15 in GLOMAP-mode. With such large uncertainty and observed variability in emission factors, $\mathrm{POM}$ : OC ratios, hygroscopic growth and secondary formation of organics, it is difficult to advocate any particular set of changes that would improve the models, though clearly there is scope to reduce the discrepancy between modelled and observed AOD without the use global emission scaling factors.

Furthermore, although tuning the emissions gave good overall agreement with observed AOD in the dominant tropical BB regions, some regional discrepancies remained. In particular, we note a low bias over West Africa and a high bias over the Congo basin during Northern Hemisphere winter. The AOD over South-east Asia and northern Australia during their BB seasons was also underestimated in our simulations, but the contribution of BB to AOD in the highlatitude boreal forests seems to be slightly overestimated. Regional biases in AOD may be caused, to some extent, by regional (or biome specific) biases in the total emission rate. Other factors may include variations in aerosol optical properties between different regions (e.g. due to different size distribution or water uptake) that may not be captured in the models. Applying a globally uniform scaling factor to account for current uncertainties in BB emission datasets is therefore not sufficient to reconcile the modelled AOD with observations. GFED version 4 (Giglio et al., 2013) has already made significant progress in addressing biases related to small fires (Randerson et al., 2012) that are difficult to identify from burned area products. Follow-on studies from this work are recommended to assess the impact of recent developments in fire emission modelling on reducing such regional biases.

Overall we conclude that GLOMAP-mode provides a good simulation of BB aerosol for modelling their impacts on radiation and climate. Impacts on $\mathrm{CCN}$ and cloud microphysics have not been evaluated here but have been assessed previously in Bellouin et al. (2013). This study does show 
clear improvements to the aerosol size distribution and composition in GLOMAP-mode that are important for aerosol indirect effects. This shows the benefits of including a more detailed representation of aerosol microphysical and chemistry processes. However, the model could merit from further improvements to BB processes, including more accurate estimates of the emission flux, the composition of emitted particles (which can vary considerably with vegetation/fuel type), and the injection height profile. We also note large uncertainties in the representation of hygroscopic growth, ageing, and absorption (including the role of brown carbon). This is partly due to the complexity of these processes and difficulties in constraining them with observations.

\section{Data availability}

The FAAM aircraft observations used in this paper (i.e. from the SAMBBA and DABEX campaigns) are publicly available from the British Atmospheric Data Centre (BADC). To apply for access, follow instructions at http://badc.nerc. ac.uk/data/faam/campaigns.html. For full details on which flights were used in this study, see Sect. 2.5 and references therein. The AERONET data used in this study are publicly available from NASA Goddard Space Flight Centre and can be downloaded from http://aeronet.gsfc.nasa.gov/ by selecting the sites and products described in Sect. 2.6. The MODIS data products used in this study are publicly available from NASA Level-1 and Atmosphere Archive and Distribution System Web Interface (LAADS web) and can be downloaded from https://ladsweb.nascom.nasa.gov/search/index. html, selecting the MODIS products detailed in Sect. 2.6. HadGEM3 model data and aircraft data from SAFARI-2000 are available on request from the lead author.

Author contributions. Ben Johnson, Justin Langridge, Eoghan Darbyshire, William Morgan, Kate Szpeck, Jennifer Brooke, and Franco Marenco contributed towards the analysis of FAAM aircraft observations from SAMBBA. Ben Johnson, James Haywood, Hugh Coe, Paulo Artaxo, and Karlan Longo were coprincipal investigators on the SAMBBA project. Jane Mulcahy, Graham Mann, Nicolas Bellouin, Mohit Dalvi, and Ben Johnson contributed to the implementation of the GLOMAP-mode aerosol scheme in HadGEM3. Ben Johnson ran the HadGEM3 model experiments, analysed the model output, and obtained and analysed the AERONET and MODIS data. Ben Johnson prepared the manuscript with input from co-authors.

Acknowledgements. The Facility for Airborne Atmospheric Measurement (FAAM) BAe-146 Atmospheric Research Aircraft is jointly funded by the Met Office and Natural Environment Research Council and operated by DirectFlight Ltd. We would like to thank the dedicated efforts of FAAM, DirectFlight, INPE, the University of São Paulo, and the Brazilian Ministry of Science and Technology in making the SAMBBA measurement campaign possible. For
AERONET data we thank the PI investigators and their staff for establishing and maintaining the sites used in this investigation (Alta Floresta and Mongu: Brent Holben, Ilorin: Rachel T. Pinker, Chiang Mai: Serm Janjai, Bonanza Creek: John R. Van de Castle, Jabiru: Ross Mitchell). We thank Andrew Sayer and Robert Levy from Goddard Space Flight Centre for their advice with MODIS aerosol products. We thank Ville Vakkari for help in selecting data from the Welgegund station. James Haywood, Eoghan Darybshire, William Morgan, Hugh Coe, Graham Mann, and Nicolas Bellouin were funded by SAMBBA (NERC grant NE/J009822/1). Ben Johnson, James Haywood and Jane Mulcahy were funded under the Joint UK BEIS/DEFRA - Met Office Hadley Centre Climate Programme (GA01101). James Haywood was part funded by the IMPALA grant (NE/M017214/1) via Future Climates for Africa (FCA) funding provided by NERC and DFID.

Edited by: G. Myhre

Reviewed by: two anonymous referees

\section{References}

Abel, S. J., Haywood, J. M., Highwood, E. J., Li, J., and Buseck, P. R.: Evolution of biomass burning aerosol properties from an agricultural fire in southern Africa, Geophys. Res. Lett., 530, 1783, doi:10.1029/2003GL017342, 2003.

Akagi, S. K., Yokelson, R. J., Wiedinmyer, C., Alvarado, M. J., Reid, J. S., Karl, T., Crounse, J. D., and Wennberg, P. O.: Emission factors for open and domestic biomass burning for use in atmospheric models, Atmos. Chem. Phys., 11, 4039-4072, doi:10.5194/acp-11-4039-2011, 2011.

Aiken, A. C., DeCarlo, P. F., Kroll, J. H., Worsnop, D. R., Huffman, J. A., Docherty, K., Ulbrich, I. M., Mohr, C., Kimmel, J. R., Sueper, D., Sun, Y., Zhang, Q., Trimborn, A., Northway, M., Ziemann, P. J., Canagaratna, M. R., Onasch, T. B., Alfarra, M. R., Prevot, A. S. H., Dommen, J., Duplissy, J., Metzger, A., Baltensperger, U., and Jiménez, J. L.: O / C and OM / OC Ratios of Primary, Secondary, and Ambient Organic Aerosols with a High Resolution Time-of-Flight Aerosol Mass Spectrometer, Environ. Sci. Technol., 42, 4478-4485, 2008.

Allan, J. D., Morgan, W. T., Darbyshire, E., Flynn, M. J., Williams, P. I., Oram, D. E., Artaxo, P., Brito, J., Lee, J. D., and Coe, H.: Airborne observations of IEPOX-derived isoprene SOA in the Amazon during SAMBBA, Atmos. Chem. Phys., 14, 1139311407, doi:10.5194/acp-14-11393-2014, 2014.

Andreae, M. O. and Merlet, P.: Emission of trace gases and aerosols from biomass burning, Global Biogeochem. Cy., 15, 955-966, 2001.

Andreae, M. O., Rosenfeld, D., Artaxo, P., Costa, A. A., Frank, G. P., Longo, K. M., and Silva-Dias, M. A. F.: Smoking rain clouds over the Amazon, Science, 303, 1337-1342, doi:10.1126/science.1092779, 2004.

Andres, R. J. and Kasgnoc, A. D.: A time-averaged inventory of subaerial volcanic sulfur emissions, J. Geophys. Res., 103, 25251-25261, 1998.

Andrews, E., Sheridan, P. J., Fiebig, M., McComiskey, A., Ogren, J. A., Arnott, P., Covert, D., Elleman, R., Gasparini, R., Collins, D., Jonsson, H., Schmid, B., and Wang, J.: Comparison of methods 
for deriving aerosol asymmetry parameter, J. Geophys. Res., 111, D05S04, doi:10.1029/2004JD005734, 2006.

Archer-Nicholls, S., Lowe, D., Schultz, D. M., and McFiggans, G.: Aerosol-radiation-cloud interactions in a regional coupled model: the effects of convective parameterisation and resolution, Atmos. Chem. Phys., 16, 5573-5594, doi:10.5194/acp-16-55732016, 2016.

Bauer, S. E. and Menon, S.: Aerosol direct, indirect, semidirect, and surface albedo effects from sector contributions based on the IPCC AR5 emissions for preindustrial and present-day conditions, J. Geophys. Res., 117, D01206, doi:10.1029/2011JD016816, 2012.

Bellouin, N., Rae, J., Jones, A., Johnson, C., Haywood, J., and Boucher, O.: Aerosol forcing in the Climate Model Intercomparison Project (CMIP5) simulations by HadGEM2-ES and the role of ammonium nitrate, J. Geophys. Res., 116, D20206, doi:10.1029/2011JD016074, 2011.

Bellouin, N., Mann, G. W., Woodhouse, M. T., Johnson, C., Carslaw, K. S., and Dalvi, M.: Impact of the modal aerosol scheme GLOMAP-mode on aerosol forcing in the Hadley Centre Global Environmental Model, Atmos. Chem. Phys., 13, 30273044, doi:10.5194/acp-13-3027-2013, 2013.

Brito, J., Rizzo, L. V., Morgan, W. T., Coe, H., Johnson, B., Haywood, J., Longo, K., Freitas, S., Andreae, M. O., and Artaxo, P.: Ground-based aerosol characterization during the South American Biomass Burning Analysis (SAMBBA) field experiment, Atmos. Chem. Phys., 14, 12069-12083, doi:10.5194/acp-1412069-2014, 2014.

Brooke, J. K.: Airborne Observations of the Physical and Optical Properties of Atmospheric Aerosol, Met Office CASE project, $\mathrm{PhD}$ Thesis, School of Earth and Environment, University of Leeds, UK, 2014.

Boucher, O., Randall, D., Artaxo, P., Bretherton, C., Feingold, G., Forster, P., Kerminen, V.-M., Kondo, Y., Liao, H., Lohmann, U., Rasch, P., Satheesh, S. K., Sherwood, S., Stevens, B., and Zhang, X.-Y.: Clouds and Aerosols, in: Climate Change 2013: The Physical Science Basis. Contribution of Working Group I to the Fifth Assessment Report of the Intergovernmental Panel on Climate Change, edited by: Stocker, T. F., Qin, D., Plattner, G.-K., Tignor, M., Allen, S. K., Boschung, J., Nauels, A., Xia, Y., Bex, V., and Midgley, P. M., Cambridge University Press, Cambridge, UK and New York, NY, USA, 571-657, 2013.

Capes, G., Johnson, B., McFiggans, G., Williams, P. I., Haywood, J., and Coe, H.: Aging of biomass burning aerosols over West Africa: Aircraft measurements of chemical composition, microphysical properties, and emission ratios, J. Geophys. Res.Atmos., 113, D00C15, doi:10.1029/2008JD009845, 2008.

Cusack, S., Slingo, A., Edwards, J., and Wild, M.: The radiative impact of a simple aerosol climatology on the Hadley Centre climate model, Q. J. Roy. Meteor. Soc., 124, 2517-2526, 1998.

Darbyshire, E. and Johnson, B.: The South American Biomass Burning Analysis (SAMBBA) Field Experiment, SeptemberOctober 2012, Brazil, Summary booklet, Available on request from the authors, 2012.

Darbyshire, E., Morgan, W. T., Allan, J., Liu, D., Flynn, M., Dorsey, J., O'Shea, S., Trembath, J., Johnson, B., Szpek, K., Marenco, F., Haywood, J., Brito, J., Artaxo, P., Longo, K., and Coe, H.: Effect of fire regime on the physical and chemical properties of biomass burning aerosol over tropical South America - Perspectives from airborne in-situ observations during SAMBBA, in preparation, 2016.

Darmenov, A. and da Silva, A.: The Quick Fire Emissions Dataset (QFED): Documentation of versions 2.1, 2.2 and 2.4, NASA/TM-2015-104606, Vol. 38, available at: https: //gmao.gsfc.nasa.gov/pubs/docs/Darmenov796.pdf (last access: 16 Noovember 2016), 2015.

Dentener, F., Kinne, S., Bond, T., Boucher, O., Cofala, J., Generoso, S., Ginoux, P., Gong, S., Hoelzemann, J. J., Ito, A., Marelli, L., Penner, J. E., Putaud, J.-P., Textor, C., Schulz, M., van der Werf, G. R., and Wilson, J.: Emissions of primary aerosol and precursor gases in the years 2000 and 1750 prescribed data-sets for AeroCom, Atmos. Chem. Phys., 6, 4321-4344, doi:10.5194/acp-64321-2006, 2006.

Derwent, R. G., Collins, W. J., Jenkin, M. E., and Johnson, C. E.: The global distribution of secondary particulate matter in a 3D Lagrangian chemistry transport model, J. Atmos. Chem., 44, 57-95, 2003.

Diehl, T., Heil, A., Chin, M., Pan, X., Streets, D., Schultz, M., and Kinne, S.: Anthropogenic, biomass burning, and volcanic emissions of black carbon, organic carbon, and $\mathrm{SO}_{2}$ from 1980 to 2010 for hindcast model experiments, Atmos. Chem. Phys. Discuss., 12, 24895-24954, doi:10.5194/acpd-12-24895-2012, 2012.

Dubovik, O. and King, M. D.: A flexible inversion algorithm for retrieval of aerosol optical properties from Sun and sky radiance measurements, J. Geophys. Res., 105, 20673-20696, 2000.

Dubovik, O., Sinyuk, A., Lapyonok, T., Holben, B. N.,Mishchenko, M., Yang, P., Eck, F. T., Volten, H., Muñoz, O., Veihelmann, B., van der Zande, W. J., Leon, J.-F., Sorokin, M., and Slutsker, I.: Application of spheroid models to account for aerosol particle nonsphericity in remote sensing of desert dust, J. Geophys. Res.Atmos., 111, D11208, doi:10.1029/2005JD006619, 2006.

Feingold, G., Remer, L. A., Ramaprasad, J., and Kaufman, Y. J.: Analysis of smoke impact on clouds in Brazilian biomass burning regions: An extension of Twomey's approach, J. Geophys. Res., 106, 22907-22922, 2001.

Freitas, S. R., Longo, K. M., Chatfield, R., Latham, D., Silva Dias, M. A. F., Andreae, M. O., Prins, E., Santos, J. C., Gielow, R., and Carvalho Jr., J. A.: Including the sub-grid scale plume rise of vegetation fires in low resolution atmospheric transport models, Atmos. Chem. Phys., 7, 3385-3398, doi:10.5194/acp-7-3385-2007, 2007.

Giglio, L., Randerson, J. T., and van der Werf, G. R.: Analysis of daily, monthly, and annual burned area using the fourthgeneration global fire emissions database (GFED4), J. Geophys. Res.-Biogeo., 118, 317-328, doi:10.1002/jgrg.20042, 2013.

Granier, C., Bessagnet, B., Bond, T., D’Angiola, A., van der Gon, H. D., Frost, G. J., Heil, A., Kaiser, J. W., Kinne, S., Klimont, Z., Kloster, S., Lamarque, J. F., Liousse, C., Masui, T., Meleux, F., Mieville, A., Ohara, T., Raut, J. C., Riahi, K., Schultz, M. G., Smith, S. J., Thompson, A., van Aardenne, J., van der Werf, G. R., and van Vuuren, D. P.: Evolution of anthropogenic and biomass burning emissions of air pollutants at global and regional scales during the 1980-2010 period, Climatic Change, 109, 163-190, doi:10.1007/s10584-011-0154-1, 2011.

Guenther, A., Hewitt, C. N., Erickson, D., Fall, R., Geron, C., Graedel, T., Harley, P., Klinger, L., Lerdau, M., Mckay, W. A., Pierce, T., Scholes, B., Steinbrecher, R., Tallamraju, R., Taylor, 
J., and Zimmerman, P.: A global model of natural volatile organic compound emissions, J. Geophys. Res., 100, 8873-8892, 1995.

Haywood, J. and Boucher, O.: Estimates of the direct and indirect radiative forcing due to tropospheric aerosols: A review, Rev. Geophys., 38, 513-543, 2000.

Haywood, J. M., Osborne, S. R., Francis, P. N., Keil, A., Formenti, P., Andreae, M. O., and Kaye, P. H.: The mean physical and optical properties of regional haze dominated by biomass burning aerosol measured from the C-130 aircraft during SAFARI 2000, J. Geophys. Res.-Atmos., 108, 8473, doi:10.1029/2002JD002226, 2003.

Haywood, J. M., Pelon, J., Formenti, P., Bharmal, N., Brooks, M., Capes, G., Chazette, P., Chou, C., Christopher, S., Coe, H., Cuesta, J., Derimian, Y., Desboeufs, K., Greed, G., Harrison, M., Heese, B., Highwood, E. J., Johnson, B., Mallet, M., Marticorena, B., Marsham, J., Milton, S., Myhre, G., Osborne, S. R., Parker, D. J., Rajot, J.-L., Schulz, M., Slingo, A., Tanré, D., and Tulet, P.: Overview of the Dust and Biomass-burning Experiment and African Monsoon Multidisciplinary Analysis Special Observing Period-0, J. Geophys. Res., 113, D00C17, doi:10.1029/2008JD010077, 2008.

Hewitt, H. T., Copsey, D., Culverwell, I. D., Harris, C. M., Hill, R. S. R., Keen, A. B., McLaren, A. J., and Hunke, E. C.: Design and implementation of the infrastructure of HadGEM3: the nextgeneration Met Office climate modelling system, Geosci. Model Dev., 4, 223-253, doi:10.5194/gmd-4-223-2011, 2011.

Hsu, N. C., Tsay, S.-C., King, M. D., and Herman, J. R.: Aerosol properties over bright-reflecting source regions, IEEE T. Geosci. Remote, 42, 557-569, doi:10.1109/TGRS.2004.824067, 2004.

Hsu, N. C., Tsay, S.-C., King, M. D., and Herman, J. R.: Deep Blue retrievals of Asian aerosol properties during ACE-Asia, IEEE T. Geosci. Remote, 44, 3180-3195, doi:10.1109/TGRS.2006.879540, 2006

Ichoku, C. and Ellison, L.: Global top-down smoke-aerosol emissions estimation using satellite fire radiative power measurements, Atmos. Chem. Phys., 14, 6643-6667, doi:10.5194/acp14-6643-2014, 2014.

Johnson, B. T., Heese, B., McFarlane, S., Chazette, P., Jones, A., and Bellouin, N.: Vertical distribution and radiative forcing of mineral dust and biomass-burning aerosols over West Africa during DABEX, J. Geophys. Res., 113, D00C12, doi:10.1029/2008JD009848, 2008a.

Johnson, B. T., Osborne, S. R., Haywood, J. M., and Harrison, M. A. J.: Aircraft measurements of biomass burning aerosol over West Africa during DABEX, J. Geophys. Res.-Atmos., 113, D00C06, doi:10.1029/2007JD009451, 2008b.

Johnston, F. H., Henderson, B., Chen, Y., Randerson, J. T., Marlier, M., DeFries, R. S., Kinney, P., Bowman, D. M. J. S., and Brauer, M.: Estimated Global Mortality Attributable to Smoke from Landscape Fires, Environ. Health Persp., 120, 695-701, doi:10.1289/ehp.1104422, 2012.

Jolleys, M. D., Coe, H., McFiggans, G., Capes, G., Allan, J. D., Crosier, J., Williams, P. I., Allen, G., Bower, K. N., Jimenez, J. L., Russell, L. M., Grutter, M., and Baumgardner, D.: Characterizing the Aging of Biomass Burning Organic Aerosol by Use of Mixing Ratios: A Meta-analysis of Four Regions, Environ. Sci. Technol., 46, 13093-13102, doi:10.1021/es302386v, 2012.

Jones, A., Roberts, D. L., Woodage, M. J., and Johnson, C. E.: Indirect sulphate aerosol forcing in a climate model with an in- teractive sulphur cycle, J. Geophys. Res., 106, 20293-20310, doi:10.1029/2000JD000089, 2001.

Jones, A., Haywood, J. M., and Boucher, O.: Aerosol forcing, climate response and climate sensitivity in the Hadley Centre climate model, J. Geophy. Res., 112, D20211, doi:10.1029/2007JD008688, 2007.

Kahn, R. A., Chen, Y., Nelson, D. L., Leung, F.-Y., Li, Q., Diner, D. J., and Logan, J. A.: Wildfire smoke injection heights: two perspectives from space, Geophys. Res. Lett., 35, 18-21, doi:10.1029/2007GL032165, 2008.

Kaiser, J. W., Heil, A., Andreae, M. O., Benedetti, A., Chubarova, N., Jones, L., Morcrette, J.-J., Razinger, M., Schultz, M. G., Suttie, M., and van der Werf, G. R.: Biomass burning emissions estimated with a global fire assimilation system based on observed fire radiative power, Biogeosciences, 9, 527-554, doi:10.5194/bg-9-527-2012, 2012.

Kaufman, Y. J., Hobbs, P. V., Kirchoff, V. W. J. H., Artaxo, P., Remer, L. A., Holben, B. N., King, M. D., Ward, D. E., Prins, E. M., Longo, K. M., and Mattos, L. F.: Smoke, Clouds, and Radiation-Brazil (SCAR-B) Experiment, J. Geophys. Res., 103, 31783-31808, 1998.

Kettle, A., Andreae, M., Amouroux, D., Andreae, T., Bates, T., Berresheim, H., Bingemer, H., Boniforti, R., Curran, M., DiTullio, G., Helas, G., Jones, G., Keller, M., Kiene, R., Leck, C., Levasseur, M., Malin, G., Maspero, M., Matrai, P., McTaggart, A., Mihalopoulos, N., Nguyen, B., Novo, A., Putaud, J., Rapsomanikis, S., Roberts, G., Schebeske, G., Sharma, S., Sim, R., Staubes, R., Turner, S., and Uher, G.: A global database of sea surface dimethylsulfide (DMS) measurements and a procedure to predict sea surface DMS as a function of latitude, longitude and month, Global Biogeochem. Cy., 13, 399-444, 1999.

Kolusu, S. R., Marsham, J. H., Mulcahy, J., Johnson, B., Dunning, C., Bush, M., and Spracklen, D. V.: Impacts of Amazonia biomass burning aerosols assessed from short-range weather forecasts, Atmos. Chem. Phys., 15, 12251-12266, doi:10.5194/acp-15-12251-2015, 2015.

Koren, I., Martins, J. V., Remer, L. A., and Afargan, H.: Smoke invigoration versus inhibition of clouds over the amazon, Science, 321, 946-949, doi:10.1126/science.1159185, 2008.

Kotchenruther, R. A. and Hobbs, P. V.: Humidification factors of aerosols from biomass burning in Brazil, J. Geophys. Res., 103, 32081-32089, 1998.

Kulmala, M., Laaksonen, A., and Pirjola, L.: Parameterizations for sulfuric acid/water nucleation rates, J. Geophys. Res., 103, 83018307, doi:10.1029/97JD03718, 1998.

Lack, D. A., Cappa, C. D., Covert, D. S., Baynard, T., Massoli, P., Sierau, B., Bates, T. S., Quinn, P., Lovejoy, E. R., and Ravishankara, A. R.: Bias in filter-based aerosol light absorption measurements due to organic aerosol loading: Evidence from ambient measurements, Aerosol Sci. Tech., 42, 1033-1041, 2008.

Lamarque, J.-F., Bond, T. C., Eyring, V., Granier, C., Heil, A., Klimont, Z., Lee, D., Liousse, C., Mieville, A., Owen, B., Schultz, M. G., Shindell, D., Smith, S. J., Stehfest, E., Van Aardenne, J., Cooper, O. R., Kainuma, M., Mahowald, N., McConnell, J. R., Naik, V., Riahi, K., and van Vuuren, D. P.: Historical (1850-2000) gridded anthropogenic and biomass burning emissions of reactive gases and aerosols: methodology and application, Atmos. Chem. Phys., 10, 7017-7039, doi:10.5194/acp10-7017-2010, 2010. 
Lau, K.-M., Tsay, S. C., Hsu, C., Chin, M., Ramanathan, V., Wu, G.-X., Li, Z., Sikka, R., Holben, B., Lu, D., Chen, H., Tartari, G., Koudelova, P., Ma, Y., Huang, J., Taniguchi, K., and Zhang, R.: The joint aerosol-monsoon experiment: A new challenge for Monsoon Climate Research, B. Am. Meteorol. Soc., 89, 369383, 2008.

Levy, R. C., Remer, L. A., Mattoo, S., Vermote, E. F., and Kaufman, Y. J.: Second-generation operational algorithm: Retrieval of aerosol properties over land from inversion of Moderate Resolution Imaging Spectroradiometer spectral reflectance, J. Geophys. Res., 112, D13211, doi:10.1029/2006JD007811, 2007.

Levy, R. C., Remer, L. A., Kleidman, R. G., Mattoo, S., Ichoku, C., Kahn, R., and Eck, T. F.: Global evaluation of the Collection 5 MODIS dark-target aerosol products over land, Atmos. Chem. Phys., 10, 10399-10420, doi:10.5194/acp-10-10399-2010, 2010.

Levy, R. C., Mattoo, S., Munchak, L. A., Remer, L. A., Sayer, A. M., Patadia, F., and Hsu, N. C.: The Collection 6 MODIS aerosol products over land and ocean, Atmos. Meas. Tech., 6, 29893034, doi:10.5194/amt-6-2989-2013, 2013.

Liousse, C., Guillaume, B., Grégoire, J. M., Mallet, M., Galy, C., Pont, V., Akpo, A., Bedou, M., Castéra, P., Dungall, L., Gardrat, E., Granier, C., Konaré, A., Malavelle, F., Mariscal, A., Mieville, A., Rosset, R., Serça, D., Solmon, F., Tummon, F., Assamoi, E., Yoboué, V., and Van Velthoven, P.: Updated African biomass burning emission inventories in the framework of the AMMAIDAF program, with an evaluation of combustion aerosols, Atmos. Chem. Phys., 10, 9631-9646, doi:10.5194/acp-10-96312010, 2010.

Liss, P. and Merlivat, L.: The Role of Air-Sea Exchange in Geochemical Cycling, chap. Air-sea gas exchange rates: Introduction and synthesis, edited by: Buat-Ménard, Springer Netherlands, 113-127, doi:10.1007/978-94-009-4738-2_5, 1986.

Magi, B. I. and Hobbs, P. V.: Effects of humidity on aerosols in southern Africa during the biomass burning season, J. Geophys. Res., 108, 8495, doi:10.1029/2002JD002144, 2003.

Malavelle, F., Pont, V., Mallet, M., Solmon, F., Johnson, B., Leon, J.-F., and Liousse, C.: Simulation of aerosol radiative effects over West Africa during DABEX and AMMA SOP-0, J. Geophys. Res., 116, D08205, doi:10.1029/2010JD014829, 2011.

Mann, G. W., Carslaw, K. S., Spracklen, D. V., Ridley, D. A., Manktelow, P. T., Chipperfield, M. P., Pickering, S. J., and Johnson, C. E.: Description and evaluation of GLOMAP-mode: a modal global aerosol microphysics model for the UKCA composition-climate model, Geosci. Model Dev., 3, 519-551, doi:10.5194/gmd-3-519-2010, 2010.

Mann, G. W., Carslaw, K. S., Reddington, C. L., Pringle, K. J., Schulz, M., Asmi, A., Spracklen, D. V., Ridley, D. A., Woodhouse, M. T., Lee, L. A., Zhang, K., Ghan, S. J., Easter, R. C., Liu, X., Stier, P., Lee, Y. H., Adams, P. J., Tost, H., Lelieveld, J., Bauer, S. E., Tsigaridis, K., van Noije, T. P. C., Strunk, A., Vignati, E., Bellouin, N., Dalvi, M., Johnson, C. E., Bergman, T., Kokkola, H., von Salzen, K., Yu, F., Luo, G., Petzold, A., Heintzenberg, J., Clarke, A., Ogren, J. A., Gras, J., Baltensperger, U., Kaminski, U., Jennings, S. G., O’Dowd, C. D., Harrison, R. M., Beddows, D. C. S., Kulmala, M., Viisanen, Y., Ulevicius, V., Mihalopoulos, N., Zdimal, V., Fiebig, M., Hansson, H.-C., Swietlicki, E., and Henzing, J. S.: Intercomparison and evaluation of global aerosol microphysical properties among AeroCom models of a range of complexity, Atmos. Chem. Phys., 14, 4679-4713, doi:10.5194/acp-14-4679-2014, 2014.

Mao, J., Horowitz, L. W., Naik, V., Fan, S., Liu, J., and Fiore, A. M.: Sensitivity of tropospheric oxidants to biomass burning emissions: implications for radiative forcing, Geophys. Res. Lett., 40, 1241-1246, doi:10.1002/grl.50210, 2013.

Marenco, F., Johnson, B., Langridge, J. M., Mulcahy, J., Benedetti, A., Remy, S., Jones, L., Szpek, K., Haywood, J., Longo, K., and Artaxo, P.: On the vertical distribution of smoke in the Amazonian atmosphere during the dry season, Atmos. Chem. Phys., 16, 2155-2174, doi:10.5194/acp-16-2155-2016, 2016.

Marlier, M. E., DeFries, S. R., Voulgarakis, A., Kinney, P. L., Randerson, J. T., Shindell, D. T., Chen, Y., and Faluvegi, G.: El Nino and health risks from landscape fire emissions in southeast Asia, Nature Climate Change, 3, 131-136, doi:10.1038/nclimate1658, 2013.

Martin, S. T., Andreae, M. O., Artaxo, P., Baumgardner, D., Chen, Q., Goldstein, A. H., Guenther, A., Heald, C. L., Mayol Bracero, O. L., McMurry, P. H., Pauliquevis, T., Pöschl, U., Prather, K. A., Roberts, G. C., Saleska, S. R., Silva-Dias, M. A., Spracklen, D. V., Swietlicki, E., and Trebs, I.: Sources and properties of Amazonian aerosol particles, Rev. Geophys., 48, RG2002, doi:10.1029/2008RG000280, 2010.

Mercado, L., Bellouin, N., Stich, S., Boucher, O., Huntingford, C., Wild, M., and Wild, P.: Impacts of changes in diffuse radiation on the global land carbon sink, Nature, 458, 01014-01018, doi:10.1038/nature07949, 2009.

Milton, S. F., Greed G., Brooks, M. E., Haywood, J., Johnson, B., Allan, R. P., Slingo, A., and Grey, W. M. F.: Modeled and observed atmospheric radiation balance during the West African dry season: Role of mineral dust, biomass burning aerosol, and surface albedo, J. Geophys. Res., 113, D00C02, doi:10.1029/2007JD009741, 2008.

Morgan, W., Allan, J., Flynn, M., Darbyshire, E., Liu, D., Szpek, K., Langridge J., Johnson, B., Haywood, J., Longo, K. M., Artaxo, P., and Coe, H.: Transformation of aerosol chemical composition and resultant impact on climate during the South American Biomass Burning Analysis (SAMBBA), iCACGP/IGAC2014 Science Conference on Atmospheric Chemistry, Brazil Natal, 22-26 September 2014.

Morgenstern, O., Braesicke, P., O’Connor, F. M., Bushell, A. C., Johnson, C. E., Osprey, S. M., and Pyle, J. A.: Evaluation of the new UKCA climate-composition model - Part 1: The stratosphere, Geosci. Model Dev., 2, 43-57, doi:10.5194/gmd-2-432009, 2009.

Myhre, G., Hoyle, C. R., Berglen, T. F., Johnson, B. T., and Haywood, J. M.: Modeling of the solar radiative impact of biomass burning aerosols during the Dust and Biomassburning Experiment (DABEX), J. Geophys. Res., 113, D00C16, doi:10.1029/2008JD009857, 2008.

Myhre, G., Samset, B. H., Schulz, M., Balkanski, Y., Bauer, S., Berntsen, T. K., Bian, H., Bellouin, N., Chin, M., Diehl, T., Easter, R. C., Feichter, J., Ghan, S. J., Hauglustaine, D., Iversen, T., Kinne, S., Kirkevåg, A., Lamarque, J.-F., Lin, G., Liu, X., Lund, M. T., Luo, G., Ma, X., van Noije, T., Penner, J. E., Rasch, P. J., Ruiz, A., Seland, Ø., Skeie, R. B., Stier, P., Takemura, T., Tsigaridis, K., Wang, P., Wang, Z., Xu, L., Yu, H., Yu, F., Yoon, J.-H., Zhang, K., Zhang, H., and Zhou, C.: Radiative forcing of the direct aerosol effect from AeroCom Phase II simulations, 
Atmos. Chem. Phys., 13, 1853-1877, doi:10.5194/acp-13-18532013, 2013.

Ng, N. L., Canagaratna, M. R., Zhang, Q., Jimenez, J. L., Tian, J., Ulbrich, I. M., Kroll, J. H., Docherty, K. S., Chhabra, P. S., Bahreini, R., Murphy, S. M., Seinfeld, J. H., Hildebrandt, L., Donahue, N. M., DeCarlo, P. F., Lanz, V. A., Prévôt, A. S. H., Dinar, E., Rudich, Y., and Worsnop, D. R.: Organic aerosol components observed in Northern Hemispheric datasets from Aerosol Mass Spectrometry, Atmos. Chem. Phys., 10, 46254641, doi:10.5194/acp-10-4625-2010, 2010.

O'Connor, F. M., Johnson, C. E., Morgenstern, O., Abraham, N. L., Braesicke, P., Dalvi, M., Folberth, G. A., Sanderson, M. G., Telford, P. J., Voulgarakis, A., Young, P. J., Zeng, G., Collins, W. J., and Pyle, J. A.: Evaluation of the new UKCA climatecomposition model - Part 2: The Troposphere, Geosci. Model Dev., 7, 41-91, doi:10.5194/gmd-7-41-2014, 2014.

Ott, L., Duncan, B., Pawson, S., Colarco, P. R., Chin, M., Randles, C., Diehl, T., and Nielsen, E.: The influence of the 2006 Indonesian biomass burning aerosols on tropical dynamics studied with the GEOS-5 AGCM, J. Geophys. Res., 115, D14121, doi:10.1029/2009JD013181, 2010.

Pacifico, F., Folberth, G. A., Sitch, S., Haywood, J. M., Rizzo, L. V., Malavelle, F. F., and Artaxo, P.: Biomass burning related ozone damage on vegetation over the Amazon forest: a model sensitivity study, Atmos. Chem. Phys., 15, 2791-2804, doi:10.5194/acp15-2791-2015, 2015.

Petrenko, M., Kahn, R., Chin, M., Soja, A., Kucsera, T., and Harshvardhan, N.: The use of satellite-measured aerosol optical depth to constrain biomass burning emissions source strength in the global model GOCART, J. Geophys. Res., 117, D18212, doi:10.1029/2012JD017870, 2012.

Polashenski, C. M., Dibb, J. E., Flanner, M. G., Chen, J. Y., Courville, Z. R., Lai, A. M., Schauer, J. S., Shafer, M. M., and Bergin, M.: Neither dust nor black carbon causing apparent albedo decline in Greenland's dry snow zone; implications for MODIS C5 surface reflectance, Geophys. Res. Lett., 42, 93199327, doi:10.1002/2015GL065912, 2015.

Ramanathan, V. and Carmichael, G.: Global and regional climate changes due to black carbon, Nat. Geosci., 1, 221-227, doi:10.1038/ngeo156, 2008.

Ramanathan, V., Crutzen, P. J., Kiehl, J. T., and Rosenfeld, D.: Aerosols, climate, and the hydrological cycle, Science, 294, 2119-2124, 2001.

Randerson, J. T., Chen, Y., van der Werf, G. R., Rogers, B. M., and Morton, D. C.: Global burned area and biomass burning emissions from small fires, J. Geophys. Res., 117, G04012, doi:10.1029/2012JG002128, 2012.

Randles, C. and Ramaswamy, V.: Absorbing aerosols over Asia: A Geophysical Fluid Dynamics Laboratory general circulation model sensitivity study of model response to aerosol optical depth and aerosol absorption, J. Geophys. Res., 113, D21203, doi:10.1029/2008JD010140, 2008.

Rap, A., Spracklen, D. V., Mercado, L., Reddington, C. L., Haywood, J. M., Ellis, R. J., Phillips, O. L., Artaxo, P., Bonal, D., Coupe, N. R., and Butt, N.: Fires increase Amazon forest productivity through increases in diffuse radiation, Geophys. Res. Lett., 42, 4654-4662, doi:10.1002/2015GL063719, 2015.

Reddington, C. L., Butt, E. W., Ridley, D. A., Artaxo, P., Morgan, W. T., Coe, H., and Spracklen, D. V.: Air quality and human health improvements from reductions in deforestation-related fire in Brazil, Nat. Geosci., 8, 768-771, doi:10.1038/ngeo2535, 2015.

Reddington, C. L., Spracklen, D. V., Artaxo, P., Ridley, D. A., Rizzo, L. V., and Arana, A.: Analysis of particulate emissions from tropical biomass burning using a global aerosol model and long-term surface observations, Atmos. Chem. Phys., 16, 1108311106, doi:10.5194/acp-16-11083-2016, 2016.

Reid, J. S., Koppmann, R., Eck, T. F., and Eleuterio, D. P.: A review of biomass burning emissions part II: intensive physical properties of biomass burning particles, Atmos. Chem. Phys., 5, 799825, doi:10.5194/acp-5-799-2005, 2005a.

Reid, J. S., Eck, T. F., Christopher, S. A., Koppmann, R., Dubovik, O., Eleuterio, D. P., Holben, B. N., Reid, E. A., and Zhang, J.: A review of biomass burning emissions part III: intensive optical properties of biomass burning particles, Atmos. Chem. Phys., 5, 827-849, doi:10.5194/acp-5-827-2005, 2005b.

Remer, L., Kaufman, Y., Tanre, D., Mattoo, S., Chu, D., Martins, J., Li, R.-R., Ichoku, C., Levy, R. C., Kleidman, R. G., Eck, T. F., Vermote, E., and Holben, B. N.: The MODIS aerosol algorithm, products, and validation, J. Atmos. Sci., 62, 947-973, 2005.

Reynolds, R. W., Smith, T. M., Liu, C., Chelton, D. B., Casey, K. S., and Schlax, M. G.: Daily High-Resolution-Blended Analyses for Sea Surface Temperature, J. Climate, 20, 5473-5496, doi:10.1175/2007JCLI1824.1, 2007.

Saleh, R., Robinson, E. S., Tkacik, D. S., Ahern, A. T., Liu, S., Aiken, A. C., Sullivan, R. C., Presto, A. A., Dubey, M. K., Yokelson, R. J., Donahue, N. M., and Robinson, A. L.: Brownness of organics in aerosols from biomass burning linked to their black carbon content, Nat. Geosci., 7, 647-650, 2014.

Samset, B. H., Myhre, G., Schulz, M., Balkanski, Y., Bauer, S., Berntsen, T. K., Bian, H., Bellouin, N., Diehl, T., Easter, R. C., Ghan, S. J., Iversen, T., Kinne, S., Kirkevåg, A., Lamarque, J.F., Lin, G., Liu, X., Penner, J. E., Seland, Ø., Skeie, R. B., Stier, P., Takemura, T., Tsigaridis, K., and Zhang, K.: Black carbon vertical profiles strongly affect its radiative forcing uncertainty, Atmos. Chem. Phys., 13, 2423-2434, doi:10.5194/acp-13-24232013, 2013.

Sayer, A. M., Munchak, L. A., Hsu, N. C., Levy, R. C., Bettenhausen, C., and Jeong M.-J.: MODIS Collection 6 aerosol products: Comparison between Aqua's e-Deep Blue, Dark Target, and "merged" data sets, and usage recommendations, J. Geophys. Res.-Atmos., 119, 13965-13989, doi:10.1002/2014JD022453, 2014.

Shindell, D. T., Lamarque, J.-F., Schulz, M., Flanner, M., Jiao, C., Chin, M., Young, P. J., Lee, Y. H., Rotstayn, L., Mahowald, N., Milly, G., Faluvegi, G., Balkanski, Y., Collins, W. J., Conley, A. J., Dalsoren, S., Easter, R., Ghan, S., Horowitz, L., Liu, X., Myhre, G., Nagashima, T., Naik, V., Rumbold, S. T., Skeie, R., Sudo, K., Szopa, S., Takemura, T., Voulgarakis, A., Yoon, J.-H., and Lo, F.: Radiative forcing in the ACCMIP historical and future climate simulations, Atmos. Chem. Phys., 13, 2939-2974, doi:10.5194/acp-13-2939-2013, 2013.

Schutgens, N. A. J., Partridge, D. G., and Stier, P.: The importance of temporal collocation for the evaluation of aerosol models with observations, Atmos. Chem. Phys., 16, 1065-1079, doi:10.5194/acp-16-1065-2016, 2016.

Sofiev, M., Ermakova, T., and Vankevich, R.: Evaluation of the smoke-injection height from wild-land fires using 
remote-sensing data, Atmos. Chem. Phys., 12, 1995-2006, doi:10.5194/acp-12-1995-2012, 2012.

Spracklen, D. V., Carslaw, K. S., Pöschl, U., Rap, A., and Forster, P. M.: Global cloud condensation nuclei influenced by carbonaceous combustion aerosol, Atmos. Chem. Phys., 11, 9067-9087, doi:10.5194/acp-11-9067-2011, 2011.

Stier, P., Feichter, J., Kinne, S., Kloster, S., Vignati, E., Wilson, J., Ganzeveld, L., Tegen, I., Werner, M., Balkanski, Y., Schulz, M., Boucher, O., Minikin, A., and Petzold, A.: The aerosol-climate model ECHAM5-HAM, Atmos. Chem. Phys., 5, 1125-1156, doi:10.5194/acp-5-1125-2005, 2005.

Stokes, R. H. and Robinson, R. A.: Interactions in aqueous nonelectrolyte solutions, solute-solvent equilibria, J. Phys. Chem., 70, 2126-2131, 1966.

Swap, B., Annegarn, H. J., Suttles, J. T., Haywood, J., Helmlinger, M. C., Hely, C., Hobbs, P. V., Holben, B., Ji, J., King, M. D., Landmann, T., Maenhaut, W., Otter, L., Pak, B., Piketh, S. J., Platnick, S., Privette, J. L., Roy, D., Thompson, A. M., Ward, D., and Yokelson, R.: The Southern African Regional Science Initiative (SAFARI 2000): Overview of the dry season field campaign, S. African J. Sci., 98, 125-130, 2002.

Swietlicki, E., Hansson, H. C., Hameri, K., Svenningsson, B., Massling, A., McFiggans, G., McMurry, P., Petaja, T., Tunved, P., Gysel, M., Topping, D., Weingartner, E., Baltensperger, U., Rissler, J., Wiedensohler, A., and Kulmala, M.: Hygroscopic properties of submicrometer atmospheric aerosol particles measured with H TDMA instruments in various environments - A review, Tellus B, 60, 432-469, 2008.

Ten Hoeve, J. E., Jacobson, M. Z., and Remer, L. A.: Comparing results from a physical model with satellite and in situ observations to determine whether biomass burning aerosols over the Amazon brighten or burn off clouds, J. Geophys. Res., 117, D08203, doi:10.1029/2011JD016856, 2012.

Tiitta, P., Vakkari, V., Croteau, P., Beukes, J. P., van Zyl, P. G., Josipovic, M., Venter, A. D., Jaars, K., Pienaar, J. J., Ng, N. L., Canagaratna, M. R., Jayne, J. T., Kerminen, V.-M., Kokkola, H., Kulmala, M., Laaksonen, A., Worsnop, D. R., and Laakso, L.: Chemical composition, main sources and temporal variability of PM1 aerosols in southern African grassland, Atmos. Chem. Phys., 14, 1909-1927, doi:10.5194/acp-14-1909-2014, 2014.

Tosca, M. G., Randerson, J. T., Zender, C. S., Flanner, M. G., and Rasch, P. J.: Do biomass burning aerosols intensify drought in equatorial Asia during El Niño?, Atmos. Chem. Phys., 10, 35153528, doi:10.5194/acp-10-3515-2010, 2010.

Tosca, M. G., Randerson, J. T., Zender, C. S., Nelson, D. L., Diner, D. J., and Logan, J. A.: Dynamics of fire plumes and smoke clouds associated with peat and deforestation fires in Indonesia, J. Geophys. Res., 116, 1-14, doi:10.1029/2010JD015148, 2011.

Tosca, M. G., Randerson, J. T., and Zender, C. S.: Global impact of smoke aerosols from landscape fires on climate and the Hadley circulation, Atmos. Chem. Phys., 13, 5227-5241, doi:10.5194/acp-13-5227-2013, 2013.

Tosca, M. G., Diner, D. J., Garay, M. J., and Kalashnikova, O. V.: Observational evidence of fire-driven reduction of cloud fraction in tropical Africa, J. Geophys. Res.-Atmos., 119, 8418-8432, doi:10.1002/2014JD021759, 2014.

Turpin, B. J. and Lim, H. J.: Species Contributions to PM2.5 Mass Concentrations: Revisiting Common Assumptions for Estimating Organic Mass, Aerosol Sci., 35, 602-610, 2001.
Twomey, S.: Pollution and the planetary albedo, Atmos. Environ., 8, 1251-1256, 1974.

Val Martin, M., Logan, J. A., Kahn, R. A., Leung, F.-Y., Nelson, D. L., and Diner, D. J.: Smoke injection heights from fires in North America: analysis of 5 years of satellite observations, Atmos. Chem. Phys., 10, 1491-1510, doi:10.5194/acp-10-14912010, 2010.

Val Martin, M., Kahn, R. A., Logan, J. A., Paugam, R., Wooster, M., and Ichoku, C.: Space-based observational constraints for 1D fire smoke plume-rise models, J. Geophys. Res., 117, D22204, doi:10.1029/2012JD018370, 2012.

Vakkari, V., Kerminen, V.-M., Beukes, J., Tiitta, P., van Zyl, P., Josipovic, M., Venter, A., Jaars, K., Worsnop, D., Kulmala, M., and Laakso, L.: Rapid changes in biomass burning aerosols by atmospheric oxidation, Geophys. Res. Lett., 41, 2644-2651, doi:10.1002/2014GL059396, 2014.

van der Werf, G. R., Randerson, J. T., Giglio, L., Collatz, G. J., Mu, M., Kasibhatla, P. S., Morton, D. C., DeFries, R. S., Jin, Y., and van Leeuwen, T. T.: Global fire emissions and the contribution of deforestation, savanna, forest, agricultural, and peat fires (19972009), Atmos. Chem. Phys., 10, 11707-11735, doi:10.5194/acp10-11707-2010, 2010.

Voulgarakis, A. and Field, R. D.: Fire influences on atmospheric composition, air quality, and climate, Curr. Pollut. Rep., 1, 7081, doi:10.1007/s40726-015-0007-z, 2015.

Walters, D. N., Williams, K. D., Boutle, I. A., Bushell, A. C., Edwards, J. M., Field, P. R., Lock, A. P., Morcrette, C. J., Stratton, R. A., Wilkinson, J. M., Willett, M. R., Bellouin, N., BodasSalcedo, A., Brooks, M. E., Copsey, D., Earnshaw, P. D., Hardiman, S. C., Harris, C. M., Levine, R. C., MacLachlan, C., Manners, J. C., Martin, G. M., Milton, S. F., Palmer, M. D., Roberts, M. J., Rodríguez, J. M., Tennant, W. J., and Vidale, P. L.: The Met Office Unified Model Global Atmosphere 4.0 and JULES Global Land 4.0 configurations, Geosci. Model Dev., 7, 361-386, doi:10.5194/gmd-7-361-2014, 2014.

Ward, D. S., Kloster, S., Mahowald, N. M., Rogers, B. M., Randerson, J. T., and Hess, P. G.: The changing radiative forcing of fires: global model estimates for past, present and future, Atmos. Chem. Phys., 12, 10857-10886, doi:10.5194/acp12-10857-2012, 2012.

Whitehead, J. D., Irwin, M., Allan, J. D., Good, N., and McFiggans, G.: A meta-analysis of particle water uptake reconciliation studies, Atmos. Chem. Phys., 14, 11833-11841, doi:10.5194/acp-1411833-2014, 2014.

Williams, K. D., Harris, C. M., Bodas-Salcedo, A., Camp, J., Comer, R. E., Copsey, D., Fereday, D., Graham, T., Hill, R., Hinton, T., Hyder, P., Ineson, S., Masato, G., Milton, S. F., Roberts, M. J., Rowell, D. P., Sanchez, C., Shelly, A., Sinha, B., Walters, D. N., West, A., Woollings, T., and Xavier, P. K.: The Met Office Global Coupled model 2.0 (GC2) configuration, Geosci. Model Dev., 8, 1509-1524, doi:10.5194/gmd-8-1509-2015, 2015.

Woodward, S.: Modelling the atmospheric life cycle and radiative impact of mineral dust in the Hadley Centre climate model, J. Geophys. Res., 106, 18155-18166, 2001.

Woodward, S.: Mineral Dust in HadGEM2, Hadley Centre Technical Note 87, Met Office Hadley Centre for Climate Change, Exeter, United Kingdom, https://digital.nmla.metoffice.gov.uk/ file/sdb:digitalFilel5fe342b8-e5c1-4992-89fd-1cfd6c05bf8a/ (last access: 16 November 2016), 2011. 
World Climate Programme (WCP): Report of the experts meeting on aerosols and their climatic effects, edited by: Deepak, A. and Gerber, H. G., World Meteorological Organization, Geneva, Switzerland, Rep. WCP-55, 107 pp., 1983.

Wu, P., Christidis, N., and Stott, P.: Anthropogenic impact on Earth's hydrological cycle, Nature Climate Change, 3, 807-10, doi:10.1038/nclimate1932, 2013.
Zhang, Y., Fu, R., Yu, H., Qian, Y., Dickinson, R., Silva Dias, M. A. F., da Silva Dias, P. L., and Fernandes, K.: Impact of biomass burning aerosol on the monsoon circulation transition over Amazonia, Geophys. Res. Lett., 36, L10814, doi:10.1029/2009GL037180, 2009. 